\title{
Offline and Online Search in Used Durables Markets
}

\author{
Sonika Singh \\ Lecturer of Marketing \\ University of Technology, Sydney \\ PO Box 123 Broadway \\ NSW 2007, Australia \\ Sonika.Singh@uts.edu.au \\ +61-2 9514-3259
}

Brian T. Ratchford

Charles \& Nancy Davidson Professor of Marketing

Jindal School of Management

The University of Texas at Dallas

Richardson, TX 75080, USA

Brian.ratchford@utdallas.edu

$+1-972-883-5975$

Ashutosh Prasad ${ }^{1}$

Associate Professor of Marketing

Jindal School of Management

The University of Texas at Dallas

Richardson, TX 75080, USA

aprasad@utdallas.edu

$+1-972-883-2027$

\footnotetext{
${ }^{1}$ Corresponding author. The authors thank Yuanping Ying, the Editor Shankar Ganesan, and two anonymous referees, and seminar participants at Cambridge University, Governors State University, Ozyegin University, University of Technology Sydney, and the 2011 Marketing Science Conference in Houston for their helpful comments. Authors contributed equally.
} 


\title{
Offline and Online Search in Used Durables Markets
}

\begin{abstract}
This study examines how different information sources are used by consumers prior to their purchase of used durable goods, specifically used cars. We examine how online and offline search are related. Categories of online sources are dealer websites and resale websites, and of offline sources are print media and dealer visits. Prior research on new car purchases finds that online sources substitute for traditional, offline sources such as dealer visits. We examine whether this theory extends to used-car purchases and distinguish between dealer websites and resale websites (a distinction relevant to used-goods markets) by collecting data from a sample of used-car buyers. Because search in different sources can be interrelated, and due to data censoring, we build and estimate a simultaneous equations Tobit model. In contrast to existing research, we find that online search on dealer websites is complementary to and not a substitute for dealer visits. This complementary effect highlights the importance of dealers' web presence in used markets.
\end{abstract}

Keywords: Used goods; Automobiles; Search; Internet; Simultaneous equations Tobit. 


\section{Introduction}

The automobile category has great economic significance, a large portion of which comes from used car sales. According to the US Bureau of Transportation Statistics (www.bts.gov), the average transaction price was $\$ 8,786$ for used vehicles and $\$ 26,850$ for new vehicles in 2011 , but used vehicles had over three times the sales volume of new vehicles. Thus, transaction values for new and used vehicles each exceeded $\$ 300$ billion. However, there has been less investigation of consumer search for used cars, compared to a well-established literature examining consumer search in the new automobile category which finds for example that individuals differ in their use of the Internet (e.g., Klein and Ford 2003; Ratchford et al. 2003, 2007). Furthermore, while existing studies examine substitution between information sources during search, a drawback is that they employ separable functional forms for the function that relates time with each source to information gained and, thus do not accommodate complementarity between sources.

From the consumer's perspective, search in used car purchases can have additional benefits compared to search in new car purchases by reducing the greater uncertainty in used car purchases, which occurs due to several factors: First, used car transactions involve asymmetric information due to unobserved maintenance, history and mechanical defects which makes the quality uncertain to the buyer even for the same make and model (Akerlof 1970). Second, the availability of a desired make and model of a used car is more random. While new car dealers provide a dedicated location and inventory for purchasing, used cars are advertised as they become available through different sources and by multiple sellers, including dealers and individual sellers. As a result, consumers search across various offline and online sources to find acceptable used cars (or used goods in general). Greater or less overlap of information in different sources can explain their substitutability or complementarity. Prior search literature has focused on substitutability, but as we will argue, greater uncertainty about product quality and availability in the used car market likely encourages complementary use of information sources.

Traditional offline information sources such as dealer visits and print (newspapers and magazines) continue to be widely used. Online sources are dealer and manufacturer websites and unaffiliated, third party websites. Some dealers operate websites and list their inventory online, while others do not. Unaffiliated websites are called resale websites (such as Auto Trader, eBay, etc.) While dealer websites list the inventory of used goods from the specific dealer, resale websites list used goods from franchised and non-franchised dealers as well as individual sellers. 
These also include sources such as Craigslist, auction websites, newspaper websites etc. Given the wide breadth of information that they provide, resale websites are arguably the most relevant websites for the search for used cars. Thus, this study treats dealer and resale websites as distinct rather than as a combined online source as commonly treated in the new car search literature. This enables us to obtain insights about the interrelationships between the usages of different online sources.

The existence of different types of online sources presents managers with the problem of coordinating a presence in some or all of them. Theory from new car purchase studies suggests that Internet search substitutes for traditional information sources such as dealer visits (e.g., Ratchford et al. 2003; 2007). If sources are substitutes, dealers should maintain a presence on many sources, or target consumers on selected sources, whereas complementarity between sources suggests the converse. We examine whether existing theory extends to used-car purchases and distinguish between dealer websites and resale websites (a distinction relevant to used-goods markets). Objectives of this study are to investigate:

- How does search on different online sources, namely Dealer websites and Resale websites, affect search on offline sources?

- Within the Internet medium, how does search on Dealer websites and Resale websites affect each other?

- How does the use of different information sources affect the type of seller chosen for the final purchase?

We conducted a survey of used car buyers to answer these questions. Surveys of search behavior may face the problem of recall by consumers; however, since cars are a major purchase, it is likely that consumers accurately recall their behavior. Hence survey methodology has been used extensively. The results of our study are as follows:

- First, search on dealer websites complements offline search (dealer visits and print). This is in contrast to prior findings by Ratchford et al. (2003) that online search is a substitute for dealer visits. Conforming to existing results, however, we find that search on resale websites is a substitute for offline search.

- Second, search on dealer websites is positively associated with search on resale websites, but search on resale websites is negatively associated with search on dealer websites. 
- Third, several consumer characteristics affect search in the used car market. Higher wage individuals are more likely to search on dealer websites and less likely to search offline. Older consumers are less likely to search online and more likely to visit dealers or search print. Word of mouth negatively affects search on dealer websites.

- Finally, those who purchase from individual sellers tend to be younger, buy in a lower price range, consider more models, and use resale websites; those who purchase from a dealer tend to be older, make more dealer visits, make less use of resale web sites, consider fewer models, and buy in a higher price range.

We next discuss the literature on search across multiple sources of information. Subsequent sections deal with the conceptual framework, data description and results. Finally, we provide discussions and directions for future research. Appendix A contains the survey instruments used for this study. Appendix B presents a detailed derivation of the model used in estimation as an extension of the model employed in Ratchford, et al. (2003).

\section{Background}

Consumers' pre-purchase search for product information from different information sources has received significant attention in the marketing literature. A literature review is provided by Ratchford (2008) who notes that empirical work on search for durable goods emerged over fifty years ago. From the marketer's perspective, obvious benefits in messaging, budgeting and competitiveness arise from understanding the search process and shaping it towards one's own products.

The durable goods search literature has focused on consumers' search for new cars in offline media. Table 1 presents a summary of the findings. Consumers search for information about functional attributes, expressive attributes and prices of competing models (Ratchford et al. 2001). In searching, consumers invest time and resources to determine which brands of cars deserve a serious effort to purchase. The size of this feasible set, i.e., the number of acceptable

makes and models of new cars, is influenced by prior experience and knowledge (Srinivasan and Ratchford 1991). Consumers with little knowledge or a great deal of knowledge may have less incentive to search, leading to an inverted U-shaped relationship between knowledge and search (Moorthy et al. 1997). After the search for acceptable makes and models, the consumer invests 
effort in trying to get a favorable deal on one such car (Ratchford and Srinivasan 1993). Once a satisfactory deal has been closed, the search process concludes.

$<$ Insert Table 1 here>

More recent literature looks at search in the online medium. Klein and Ford (2003) use online survey data of automobile shoppers and purchasers to examine how individuals differ in their use of the Internet and the patterns of substitution they exhibit across sources and media. They find that basic economics continues to drive information search as measured in terms of amount (time) and breadth (number of sources) of search. Their analysis of search behavior reveals an offline-online dimension of search apart from the traditional dimensions of impersonal/personal and independent/seller-dominated search.

Ratchford et al. (2003) and Ratchford et al. (2007) study the impact of online search for new cars on the use of traditional information sources. They find that Internet search substitutes for traditional search with the greatest impact on dealer visits. Both studies employ a search model where consumers allocate time among Internet and non-Internet sources to maximize the value of information, subject to time constraints. Employing a more flexible time allocation model, Kim and Ratchford (2012) find that Internet search increases much more rapidly with total search than the use of other sources, especially the dealer. In all of these models, consumers' usage of information sources to search for new automobiles is based on the assumption that the sources are substitutes, i.e., acquiring information from one source lowers the need to use another.

Sarvary and Parker (1997) study competition in the information sector, and explicitly model cases in which information sources can be complements as well as substitutes. Their game theoretic model consists of two firms selling information to a population of consumers who are heterogeneous in their willingness to pay for quality of information. The quality of information is linked to the accuracy of consumers' estimate of the mean, and consumers facing important decisions may find it beneficial to purchase from several information sellers. Depending on the reliability of information in the same product-attribute space, they find that competitive structures may accommodate complementarity or substitution patterns. This setup is applicable to the used car market where consumers face classical asymmetry problems due to differences in quality of the product and reputation of the seller. We will incorporate their results into the conceptual model discussed in the next section. 


\section{Conceptual Framework}

To analyze search for cars or other used durables, we define search of a source type as the total number of different sources used within the type, e.g., the number of dealer websites visited is a measure of search on dealer websites. This is consistent with depth of search as defined by Klein and Ford (2003). New and used durables markets differ on dimensions such as quality uncertainty, number of sellers and seller types, etc. See Table 2 for a comparison of information requirements in new and used car markets. This table is discussed in the paragraphs below.

<Insert Table 2 here>

Search for new durables (e.g. cars, computers, laptops etc.) involves search for information on makes and models (Erdem et al. 2005; Ratchford and Srinivasan 1993; Ratchford et al. 2001). New cars of a given make and model should have similar quality across franchised dealers which reduces the need to evaluate individual items. Thus, the role of information sources is to disseminate product and price information, and information about the location and other characteristics of dealers (Pauwels et al. 2011; Punj and Staelin 1983; Ratchford et al. 2003; Srinivasan and Ratchford 1991). The information can be obtained from print, word of mouth, third party information websites, dealer websites, and dealer stores (Klein and Ford 2003).

Used car quality depends on the unobserved driving and maintenance habits of its previous owners, and on the ability of dealers to screen out unsatisfactory units. As a result, used goods of the same specification (make, model, year of manufacturer etc.) differ in their evaluation. In addition to locating product, price and dealer information, buyers in used car markets have to locate available models that are for sale, and have the option to buy from a variety of dealer types beyond the franchised dealer that sells a particular type of new car.

Thus, in addition to search tasks that buyers of new cars undertake, buyers of used cars have to determine which cars are currently available, whether to buy from a new or used car dealer or individual seller, and assess the quality of the cars they locate. ${ }^{2}$ To accomplish these tasks, consumers may use a variety of online and offline sources that provide a listing of used cars for sale. Buyers can browse through listings of used items on online sources (dealer websites and resale websites) or view them in traditional sources (print or visit dealer stores). They can

\footnotetext{
2 The latter is difficult, and may require the use of risk-reduction activities (Dowling and Staelin 1994), such as buying from a reputable dealer and obtaining information on the history of cars that are candidates for purchase.
} 
also view factual information about each item, e.g., the selling price, VIN number, carfax history, seller type (individual reseller or dealer), and pictures of the used car. This detailed information is not required for the purchase of a new car.

As noted in the previous section, Sarvary and Parker (1997) provide an argument for which information sources should be complements or substitutes, contingent on circumstances. We define a source as complementary to another if its use increases with increased use of the other source, and a source as a substitute for another if its use declines with increased use of another source. Sarvary and Parker (1997) show that different information sources are more likely to be treated as complements by consumers when the reliability of their information is low and the sources of information are independent. Intuitively, noisy information requires checking a lot of sources to obtain a good basis for action, and independent information requires a lot of sources to locate a range of good alternatives. In contrast, when information sources are more reliable and their information correlated, then consumers do not need multiple sources and are more likely to see them as substitutes. Intuitively, reliable and correlated information implies that one can get essentially the same information in a number of different places, and using one source is enough. ${ }^{3}$

The used car market is one where the former case is more likely to apply. Reliability of sources is lower in the used car market than in the market for new cars because the inventory comes and goes. Whereas, the availability of a current model Honda Accord at the market price is almost guaranteed at a new car dealership, the availability of a ten year old Accord is uncertain. It might suddenly appear on eBay and be delisted within a few days. Thus a customer may search through several sources to find the listing they want in a timely manner. Also because of the variety of sources that can be employed by an advertiser, the information in the different sources is likely to be more independent for used cars than for new cars.

Based on the above characteristics of the used car market, one can hypothesize about the relationship between the variety of sources used by consumers to locate a used car. As summarized in Table 2, due to the large number of sellers, information asymmetry about product quality, lack of reliability of sources, lack of seller reputation etc., and independence of

\footnotetext{
${ }^{3}$ In the present study, Sarvary and Parker's result implies that the same two information sources could be treated by consumers as substitutes for one situation (e.g., when buying a new car) or as complements in another situation (e.g., when buying a used car). This is distinct from how consumers might always treat, for example, products like a Camry and an Accord as substitutes.
} 
information provided by different sources, it is likely that multiple online and offline sources will be consulted by many buyers. Given the above discussion, this implies that there is greater likelihood of source complementarity in the used car market. Accordingly, we hypothesize:

H1. Offline search is positively associated with online search in the used car market, i.e., the more consumers do offline search, the more they will do online search. Finding purchase candidates on different dealer or resale web sites may lead to follow up inspection of the candidates at multiple dealers, or dealers and individual sellers in the case of resale websites. Hence we hypothesize that:

$\mathrm{H} 2 \mathrm{a}$. Search on dealer websites is positively associated with offline search in the used car market.

H3a. Search on resale websites is positively associated with offline search in the used car market.

However, theory from new car search suggests plausible arguments for why the use of dealer and resale websites might substitute for offline search. Online sources can substitute for offline search because online search is more efficient and the online dealer and non-dealer channel less costly (Bakos 1998, Chen et al. 2008; Grewal et al. 2003; Ratchford et al. 2007; Zettelmeyer et al. 2006). Thus online search may allow buyers to screen a large number of alternatives efficiently, and lower the need to physically inspect a large number of cars. Thus two competing hypotheses are:

H2b. Search on dealer website is negatively associated with offline search in the used car market.

$\mathrm{H} 3 \mathrm{~b}$. Search on resale website is negatively associated with offline search in the used car market.

If buyers consult a variety of online sources to find what they want, one might expect dealer and resale websites to be complements. Thus we hypothesize that:

H4a. Search on dealer websites is positively associated with search on resale websites in the used car market.

On the other hand, more strategic buyers might direct their online search toward the type of outlet they plan to buy from: intending to buy from an individual seller or used car dealer, those who use resale web sites might avoid dealer web sites. This suggests the following hypothesis: 
H4b. Search on resale website is negatively associated with search on dealer website in the used car market.

Both tendencies might be present in different consumers in our data. That is, consumers who make extensive use of dealer web sites may also tend to consult the resale sites, but consumers intending not to buy from a dealer may avoid the dealer sites. In regressions with different sets of covariates that describe the choice of dealer and resale web sites, this could result in a positive coefficient for dealer web sites in a regression with resale sites as dependent (H4a), and a negative coefficient for resale web sites in a regression with dealer sites as dependent (H4b).

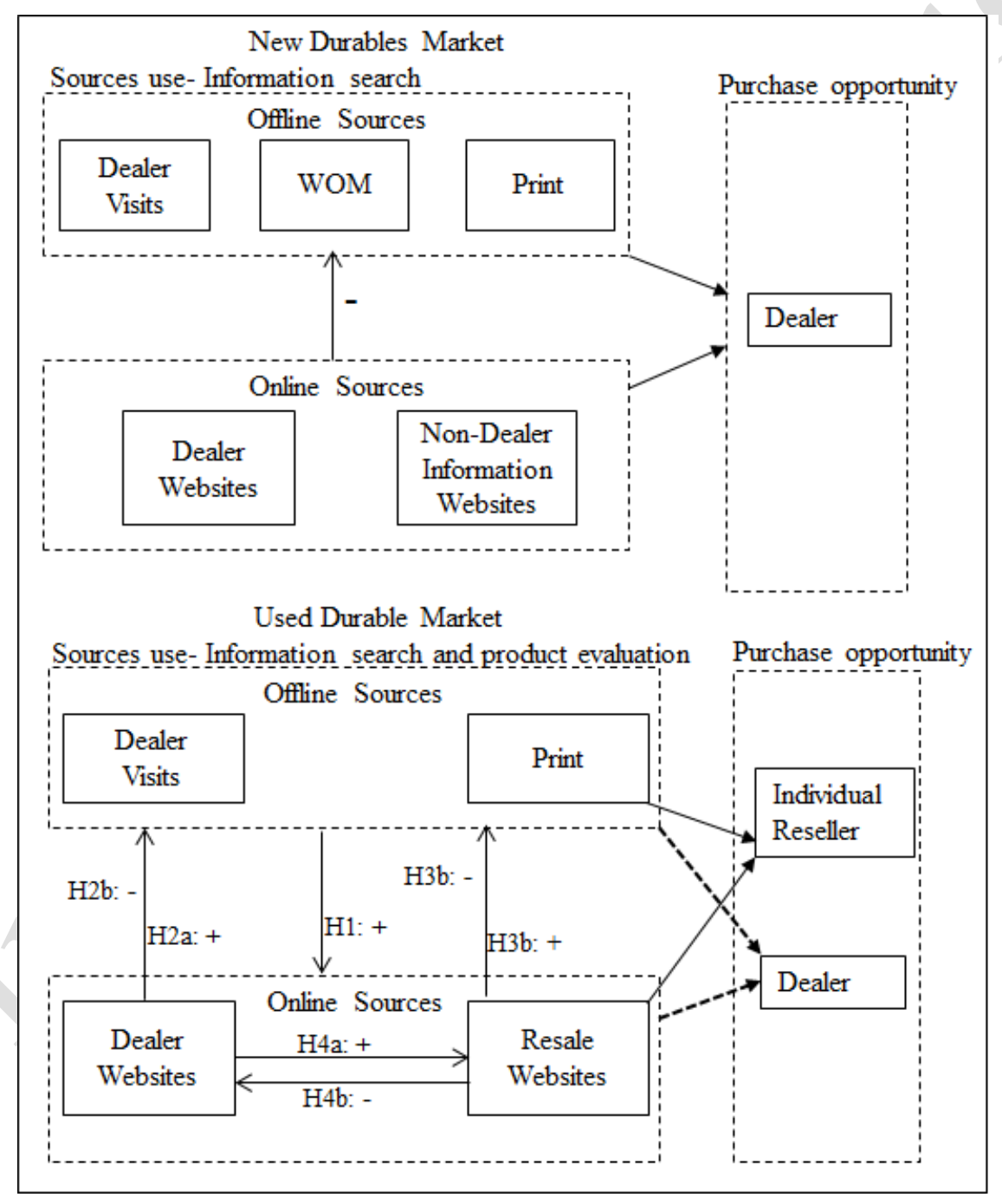

Fig. 1: Framework for Search in New and Used Durables

Thus we have two sets of hypotheses about whether online and offline search are complements or substitutes. Figure 1 summarizes the discussion in this section by illustrating the 
different hypotheses as presented here and in the new car literature. The main sources of offline information in new car market are dealer visit, WOM and print. The online sources are dealer websites and non-dealer websites. In the used car market, the main sources of offline information and product evaluation are dealer visit and print. Since WOM is limited to obtaining information only, it is not represented as a source of product evaluation in the Figure 1. The online sources of information and product evaluation in the used car market are dealer websites and resale websites.

\section{Data}

The dataset for this study was collected via a questionnaire-based survey of used car buyers over a period of 3 months beginning June, 2010. A total of 250 surveys were collected. Eleven were excluded, following prior studies (e.g., Ratchford et al. 2003), as their reported search time exceeded 60 hours.

To examine the used car search process we began by conducting depth interviews of four used car buyers, three franchised car dealers and one non-franchised car dealer. The dealers were based in a southern US city, whereas the consumers were from that city and another in the Great Lakes region. Consumers elaborated their search process, and use of Internet and non-Internet sources to locate used cars. The interviews revealed that consumers inspected the accident history, type of seller, sale price and maintenance records at auto repair outlets. Dealer interviews revealed that some dealers listed their inventory of used cars on dealer websites and advertised used cars on other sources as well. Next, a pilot survey was taken on a convenience sample of twelve used-car buyers. The final questionnaire was shortened based on feedback from the pilot survey.

Auto-repair outlets were chosen as the location to recruit participants and administer the survey rather than dealerships or used car lots, because the latter could bias the sample towards consumers who prefer dealerships or used car lots over, say, individual sellers, or prefer offline over online search. Of seven randomly selected auto repair outlets, five supported the survey. A receptionist requested used car owners to fill the survey and place them in a drop box in the waiting area.

The questionnaire is based on questionnaires of the new car search process (Ratchford et al. 2003). It is designed to capture the respondent's motivation to purchase a used car, use of various information sources, and their purchase. The various measures are based on those 
employed in prior studies (Klein and Ford 2003; Punj and Staelin 1983; Ratchford et al. 2003; Srinivasan and Ratchford 1991). The questionnaire has 6 parts (see Appendix A for a copy). Section A is about search for the used car. It records respondents' prior information about the manufacturer and the seller, the makes and models considered, the sources consulted to search for information on makes and models, and the sources used to search for and evaluate used cars. Prior information is measured by whether the respondent knew which make and seller to buy from (Ratchford et al. 2003). We classify the sources using Klein and Ford (2003) framework. The sources are traditional print, traditional retail (dealer store), online neutral/resale website (e.g. cars.com, craigslist.com) and online retail (dealer websites).

Section B focuses on the decision process to select used cars from those available in the used car market. The respondents indicate the number of visits to a specific seller and number of cars located from that seller. Respondents indicate the total number of sources consulted within a source type i.e. depth of search (Klein and Ford 2003). Respondents assessed the sellers on measures of trust and risk. These are 5-point Likert scales based on standard scales from the marketing handbook of scales. Trustworthiness is measured as competency of the seller, ability to deliver its promise, quality of cars, dependability and concern about customers. Risk has been measured as performance risk, maintenance risk, time risk and risk of buying from a given seller (Stone and Gronhaug 1993). This section includes some validation questions related to the use of information sources.

Section C deals with the respondent's used car shopping experience and captures information about make, model, price, and satisfaction with the recently purchased used car. The next three sections in the survey record the respondents' shopping enjoyment, use of Internet, prior experience with cars and demographic information. The survey measures several 'shopping enjoyment' variables about shopping in general as well as shopping for cars. These include measures such as "talking to sales people, enjoying store visit, tendency to gather information before dealer visit, price comparison and the use of the internet to make purchases." These are measured on a 5-point Likert scale, with 1 representing the lowest and 5 representing the highest agreement on that measure. Internet expertise is captured using two variables: the number of hours of Internet use per week and the years of Internet experience (Klein and Ford 2003; Ratchford et al. 2003). Hours of Internet use measures the current ability and opportunity to use the Internet, while years of Internet use is a proxy for accumulated experience with the Internet. 
Measures of first car owned and number of used and new cars bought in the past ten years provide information about the respondent's amount of experience (Punj and Staelin 1983; Ratchford et al. 2003). Content of experience is measured by questions about satisfaction with the previous car and dealer (Ratchford et al 2003). Time costs are measured by the respondent's hourly wage (Srinivasan and Ratchford 1991). Education is measured as years of school completed (Klein and Ford 2003; Ratchford et al. 2003).

Since our approach is based on prior survey designs, it rules out any measurement and method differences relative to earlier studies. Due to the difficulty of identifying potential consumers of used cars this survey design is unable to capture "in-process" measures employed in prior studies (Erdem et al. 2005; Klein and Ford 2003) in addition to post-purchase measures.

\section{Dependent Variable}

The information sources in this study are grouped into dealer visit, print, dealer websites, and resale websites. Search on manufacturer websites is grouped together with search on dealer websites because manufacturer websites typically route consumers to dealer websites for used car listings. Resale websites include newspaper websites, auction websites, third party websites and local community websites. Resale websites are used by consumers to contact different dealer types directly or indirectly to request price quotes.

Search on an information source is the dependent variable. It is operationalized as depth of search, which is the total number of different sources consulted within a source type in the external search process (Klein and Ford 2003). As an example, consider that a consumer visits Ford, GM and Honda dealers, then the depth of search for dealer visits is 3, i.e. the total number of different dealers visited. Similarly, if a consumer searches for used cars on five different auction websites, three different community websites, two different third party websites and one newspaper website then the depth of search on resale websites is 11 .

\section{<Insert Table 3 here>}

Table 3 provides a description of consumer characteristics. Consumers considered an average of 2.4 models while shopping for cars. Consumers' experience of used cars is more than their experience of new cars. $67 \%$ of the respondents are male, $64 \%$ are married and their average age is 38 years. The average, used-car sticker price is $\$ 12477$. From Table 3 we also see that consumers visited an average of 3 dealers, 5 dealer websites and 6 resale websites. This is higher than search in traditional print medium. Search on these websites is much less for new 
cars. As shown in Table 3, Ratchford et al. (2003) report that consumers in their sample visited an average of 1 dealer website and 3 resale websites. Ratchford et al. (2007) find that consumers visited an average of 2 dealers, 3 dealer websites and 2 resale websites. Consistent with reasoning in Table 2, consumers in the used car market search more than consumers in the new car market.

\section{<Insert Table 4 here>}

Table 4 displays the correlation matrix. The correlation coefficients between dealer websites and dealer visits and resale websites and dealer websites are higher than other correlations (both 0.40). Also there is a high correlation between consumers' frequency of Internet use and consumers' tendency to do price comparison (0.36).

\section{<Insert Table 5 here>}

Table 5 describes the number of makes and models considered by consumers in the sample. About $33 \%$ considered 2 makes and models and 26\% considered 3 makes and models of used cars. Furthermore, they are relatively equally split in their preference for three seller types $34 \%$ of the respondents have bought cars from new car dealers and $28 \%$ have bought from used car dealers. $30 \%$ of the respondents have bought from individual sellers - whereas fewer (7.5\%) bought from used car superstores. Coverage of the seller types in the sample reflects the national averages. $^{4}$

\section{<Insert Table 6 here>}

Table 6 shows the several information sources that were used by respondents to search for used cars and the percentage of users who used them. These sources are later aggregated into the four types as mentioned above. $70 \%$ of the respondents had visited dealers, $62 \%$ searched on dealer websites and $52 \%$ searched on local websites such as Craigslist, Ebay etc. While newspaper advertisements by dealers, and classified ads in newspapers by both dealers and individual sellers would have been the main source of information on individual cars prior to the Internet, these sources were among the least used sources for the respondents to this study. This illustrates the extent to which the Internet has replaced newspapers as an information source.

\footnotetext{
${ }^{4}$ A report by Capegemini on the U.S used car market found that for 2007, nationwide dealer shares in used car market were $37 \%$ for franchised dealers, $32 \%$ for non-franchised car dealers and $31 \%$ for individual sellers. According to CNW market research, franchised dealers had $34.3 \%$ market share in 2010. For the data in our study, franchised dealers have $34.3 \%$ market share, non-franchised dealers have $35.6 \%$ share, and individual sellers have $30.1 \%$ market share.
} 
Independent Variables - Indicators of Customer Needs

The independent variables consist of consumers' experience of buying used cars (i.e., the number of previous used-car purchases), the total number of models considered, time costs (measured as hourly wage rate), the age of the respondent, shopping enjoyment and the number of children in the household. In our sample, $38 \%$ of respondents relied on relatives and friends to find information on used cars and $23 \%$ of respondents actually bought through a family member or friend. Therefore, we control for word of mouth. We use the measure time spent consulting WOM as an independent variable in the analysis.

As seen from Table 3, the mean of consumers' inclination to engage in price comparison and gather information before visiting dealers is higher than other measures of shopping enjoyment (4.39 and 3.72 respectively).

\section{Empirical Analysis}

We estimated a linear simultaneous equation Tobit model in which the use of each source was allowed to depend on the use of the others. To accommodate cases in which a given source was not used, we define the relation between observed search on information source $j$ for consumer $i, y_{i j}$, and latent search $y_{i j}{ }^{*}$ as follows:

$$
y_{i j}=\left\{\begin{array}{lll}
y_{i j}^{*} & \text { if } & y_{i j}^{*}>0, \\
0 & \text { if } & y_{i j}^{*} \leq 0 .
\end{array}\right.
$$

If the vector of latent elements $y_{i j}^{*}$ is defined as $Y_{i}^{*}$, consumer $i$ 's use of $J$ sources can be expressed in matrix form as:

$$
\Gamma Y_{i}^{*}=X_{i}^{*} \beta+\varepsilon_{i}
$$

or equivalently as,

$$
Y_{i}^{*}=-(\Gamma-\mathrm{I}) Y_{i}^{*}+X_{i}^{*} \beta+\varepsilon_{i},
$$

where $Y_{i}^{*}$ is a $J$ element vector of latent depth of search, $\Gamma$ is a $J \times J$ matrix of coefficients with 1 's in the diagonal, I is a $J \times J$ identity matrix, $X_{i}^{*}$ is a matrix of exogenous variables to be defined below, $\beta$ is a matrix of coefficients of the exogenous variables, and $\varepsilon_{i}$ is a $J$ element vector of random errors. As shown in Appendix B, an extension of the framework presented in Ratchford, et al. (2003) can be used to derive the system of equations in Equations 2 and 3 from the firstorder conditions for optimal allocation of effort to each source. 
A more detailed version of the relationship described in Equation 3 is shown in Equation 4 (we drop the subscript for consumer $i$ for clarity). In Equation 4 the matrix of $\gamma$ coefficients reflects the interrelationship between information sources, and positive values of $\gamma_{i j}$ represent complements, while negative values represent substitutes. As explained earlier, this interrelationship is an important aspect to consider in the used car market and directly relates to the hypotheses under study.

$$
\left(\begin{array}{l}
y_{1}^{*} \\
y_{2}^{*} \\
y_{3}^{*} \\
y_{4}^{*}
\end{array}\right)=\left(\begin{array}{cccc}
\beta_{1}^{\prime} X_{1} & 0 & 0 & 0 \\
0 & \beta_{2}^{\prime} X_{2} & 0 & 0 \\
0 & 0 & \beta_{3}^{\prime} X_{3} & 0 \\
0 & 0 & 0 & \beta_{4}^{\prime} X_{4}
\end{array}\right)+\left(\begin{array}{l}
\delta_{1} E R_{1} \\
\delta_{2} E R_{2} \\
\delta_{3} E R_{3} \\
\delta_{4} E R_{4}
\end{array}\right)+\left(\begin{array}{cccc}
0 & \gamma_{12} & \gamma_{13} & \gamma_{14} \\
\gamma_{21} & 0 & \gamma_{23} & \gamma_{24} \\
\gamma_{31} & \gamma_{32} & 0 & \gamma_{34} \\
\gamma_{41} & \gamma_{42} & \gamma_{43} & 0
\end{array}\right)\left(\begin{array}{c}
y_{1}^{*} \\
y_{2}^{*} \\
y_{3}^{*} \\
y_{4}^{*}
\end{array}\right)+\left(\begin{array}{l}
\varepsilon_{1} \\
\varepsilon_{2} \\
\varepsilon_{3} \\
\varepsilon_{4}
\end{array}\right)
$$

Consumers' depth of search is observed for dealer visit $\left(y_{1}{ }^{*}\right)$, print newspapers $\left(y_{2}{ }^{*}\right)$, dealer websites $\left(y_{3}{ }^{*}\right)$, and resale websites $\left(y_{4}{ }^{*}\right)$.

In Equation 4, we divide the exogenous variables $X_{i}^{*}$ that affect the use of information sources into two categories: $X_{i}$, which are common for all information sources, and $E R$, which represent exclusion restriction variables which help to identify each equation. Kukar-Kinney et al. (2009) demonstrate that the shopping and buying motivations may be a better predictor of propensity to shop and buy online versus in stores. Therefore, specific variables were identified that affect the shopping behavior of an individual on each source. These variables are: consumers' enjoyment of dealer visits, reading car magazines, price comparison, gathering information and tendency to use the Internet. They are measured on a 5-point Likert scale. These variables, along with the helpfulness of each source, are used as exclusion restrictions to identify the model.

Table 7 shows the combination of variables that is used to identify each equation. For instance, the equation for dealer visit is identified by eliminating variables marked with a zero in Table 7 from the equation, and using only consumers' enjoyment of store visit, talking to salespeople and helpfulness of dealer visit in the equation. The latter three variables help to identify the other equations since they are excluded from them. The "helpfulness" variable, measured on a 5-point Likert scale, captures the usefulness of an information source in locating used cars. "Helpfulness" of the source acts as a mediator variable to explain how some demographic characteristics influence search and why some people use a particular source type. Consider, for example, that older people are less adept at using the Internet to find information 
and find it more helpful to physically inspect cars. Therefore they visit dealer lots. Here "helpfulness" of the source explains the relationship between age and dealer visits. Using the exclusion restriction variables, the system of simultaneous Tobit equations can be estimated.

\section{<Insert Table 7 here>}

Given the presence of zero values of $y_{i j}$ we have chosen to work with a Tobit model in which we define $y_{i j}{ }^{*}$ as latent search on information source $j$ for consumer $i$. The rationale for this modeling choice is as follows. The dependent variable, depth of search, is count data. A Poisson regression model would be a natural choice to estimate the data, but the Poisson distribution has variance equal to the mean, and as observed in the data, the variance is greater than the mean. Another possibility is using a multivariate ordinal probit model to estimate the parameters, but a critical assumption of the ordered probit is that of parallel slopes. This implies that if a variable affects the likelihood of an individual being in a category, the coefficients linking the variable to different outcomes are the same across outcomes. However, this assumption is violated because we expect WOM, age, and consumers' tendency to gather information, to differ in their association with the use of different information sources. Therefore, an ordinal model is not appropriate (Long 1997). On the other hand, the Tobit model can handle zero values, assumes a normal distribution on the error terms which can be generalized to a multivariate case, and can incorporate simultaneity. Taking into account the censoring, multivariate use of information sources and simultaneity, the simultaneous equations Tobit is appropriate.

To estimate the system of simultaneous equations with censored and limited dependent variables in Equation 4, Cameron and Trivedi (2005) suggest obtaining a reduced form and estimating it as a Tobit model. Then replace the regressors $Y_{i}$ in the structural model with their reduced form predictors and estimate the regression model. However, prior literature (Albert and Chib 1996; Chib 1992; Jang et al. 2010; Li 1998; Yang et al. 2006; Zellner 1996) suggests that we can employ Gibbs sampling and data augmentation to draw the exact posterior. The linear simultaneous equation model (SEM) is estimated conditioned on the augmented data which leads to a Markov chain Monte Carlo (MCMC) solution (Gelfand et al. 1992; Jang et al. 2010; Li 1998; Tanner and Wong 1987). This avoids a direct evaluation of the non-trivial likelihood function ( $\mathrm{Li} \mathrm{1998)}$ and avoids the use of two-step estimation approach. Using latent data augmentation and MCMC estimation facilitates recovery of structural parameters of an over- 
identified system (Jang et al. 2010) and the variance of the estimates need not be corrected for, unlike the two step estimation of simultaneous equations model. Therefore, we follow the Bayesian estimation as suggested in the prior literature.

To resolve the simultaneity issue, the $\gamma$ coefficients are estimated using a Metropolis Hastings algorithm random walk chain. Once the $\gamma$ coefficients are obtained they are rearranged to form the $\Gamma$ matrix. A noted above, $\Gamma$ is a $J \times J$ matrix whose diagonal elements are 1 and offdiagonal elements are coefficients of other endogenous variables.

We calculate $\tilde{Y}_{i}^{*}=\Gamma Y_{i}^{*}$ and obtain Equation 5 as shown:

$$
\tilde{Y}_{i}^{*}=X_{i}^{*} \beta+\varepsilon_{i}
$$

Equation 5 represents the structure of a SUR model with a multivariate normal structure on the error terms. This can be estimated using Gibbs sampler assuming the standard normalwishart priors on $\beta$ and $\Sigma$. The $\Gamma$ (matrix of the $\gamma$ coefficients), $\beta$ and $\Sigma_{\varepsilon}$ are drawn sequentially. Once these are obtained, the $y_{i} *$ are generated from the conditional multivariate truncated normal distribution (Albert and Chib 1996). The Markov chain is run twice (Koop 2003). The Markov chain is run for 25,000 iterations with 10,000 burn-in period. The variance of $\Gamma$ obtained in the first run is used as the starting value for the next run. The second run is for 30,000 iterations with 20,000 for burn-in. The acceptance rate of the chain was $51 \%$. The 10,000 stored draws were used to calculate the posterior probability distribution for the coefficients of multivariate Tobit. The stable trend of draws and plots of beta coefficients indicated that the Markov chain had converged. To ensure the stability of the estimates, simulations were performed using the data. In the simulation, the dependent variable was simulated using the observed independent variables and a set of coefficients. The model was estimated on simulated data to recover the model parameters.

At this point we might comment briefly on the interpretation of the model outlined in Equations 1-5 and the associated discussion. While the model describes a set of relationships that occur simultaneously, the relationships are meant to describe how a given dependent variable is affected by changes in any right side variable holding all else constant. In this sense the model is meant to describe causal relationships. The instrumental variables are meant to eliminate biases created by the presence of endogenous variables on the right side of various equations. If the instruments accomplish this, the model will succeed in its purpose of accurately describing how changes in the right side variables affect the dependent variables (Antonakis et al. 2010; 
Heckman and Vytlacil 2007, 2008). However, given that we have cross sectional data, it is difficult to determine whether the use of instruments has eliminated biases due to endogeneity, or whether other sources of bias such as omitted variables are present. We return to this topic in our limitations section.

\section{Results}

The analysis reveals some interesting insights about the determinants of search and the use of online sources in the used car market. Table 8 summarizes the hypotheses and whether these are supported or rejected.

\section{<Insert Table 8 here>}

\section{Online and Offline Search}

Results for the relationships between the four information sources are presented in Table 9. Because the usage of each source differs considerably, the regression coefficients in Table 9 are not directly comparable. Thus we also calculated mean-value elasticities (denoted as E below) for each estimate. Since they are the ratio of percentage changes, they are dimensionless, and therefore comparable.

Table 9 indicates that, contrary to new-car based findings in the prior literature, offline search using dealer visits is positively related to search on dealer websites $(\beta=0.59, \mathrm{E}=.37)$. Search on offline print source is also positively associated with search on dealer websites $(\beta=$ $1.89, \mathrm{E}=.20)$ as well as resale websites $(\beta=0.59, \mathrm{E}=.06)$. Thus we find support for H1. Table 9 also indicates that search on dealer websites is strongly related to dealer visits $(\beta=0.78, \mathrm{E}=$ 1.27), as well as search in print $(\beta=0.53, \mathrm{E}=4.99)$ thus supporting hypothesis $\mathrm{H} 2 \mathrm{a} .{ }^{5}$ Consistent with buyers who wish to buy from a dealer obtaining information from dealer web sites about cars available at different dealers, users of many dealer websites also tend to visit multiple dealers. This is consistent with prior findings that for expensive products, retail websites play an informational role and online search and offline purchases are complements (Pauwels et al. 2011). The positive relationships between use of print and use of dealer and resale web sites, and between dealer and resale web sites, suggests that consumers tend to cast their net widely in efforts to locate suitable cars. Consistent with the existence of uncorrelated information across these three source types, many appear to find it necessary to consult all three, tending to make them complements.

\footnotetext{
${ }^{5}$ The relatively high elasticities for print result from its relatively small mean (see Table 9).
} 


\section{$<$ Insert Table 9 here>}

The negative relationships between resale websites and dealer visits $(\beta=-0.28, \mathrm{E}=-.51)$, and between resale websites and traditional print $(\beta=-0.05, \mathrm{E}=-.52)$, provide support for $\mathrm{H} 3 \mathrm{~b}$. Similarly, dealer visits are negatively associated with search on resale websites $(\beta=-1.65, \mathrm{E}=-$ .91). These findings indicate that resale websites substitute or print and dealer visits, possibly because they are used to locate prospective individual sellers.

Table 9 shows an asymmetric impact of search within the online medium. Search on dealer websites is positively associated with search on resale websites $(\beta=0.24, \mathrm{E}=.21)$ supporting hypothesis H4a. Search on resale websites is negatively associated with search on dealer websites $(\beta=-0.02, \mathrm{E}=-.02)$ supporting hypothesis $\mathrm{H} 4 \mathrm{~b}$. While significant, the elasticity indicates that the latter effect is small. This asymmetric effect is possible because of different exogenous influences on the two types of sites, i.e., heavy users of the two sites tend to be different people. For example, the effects of exogenous factors that are presented in Table 10 (to be discussed below) indicate that users of dealer websites tend to be higher wage, younger, and non-users of word of mouth. They also tend to use resale web sites, but are probably not the heaviest users of such sites. The latter tend to rely extensively on word of mouth, search a lot of different models, and tend to have lower wage and income than heavy users of dealer web sites (see Table 10 and discussion below). On balance these results suggest that younger, higher income buyers who tend to buy from a dealer use all online sources, but not word of mouth. Other users of resale sources appear to be searching for a car from an individual reseller, and to also use word of mouth in this endeavor, but to have little interest in dealer sources. ${ }^{6}$

The results above show that in used markets, consumers evaluate the different online sources as distinct from one another. Hence, the direction of association of online and offline search differs based on the source. Furthermore, the dealer sources are complementary, which suggests that search in used durable goods markets is different from that in new durable goods markets.

\section{Consumer characteristics}

Table 10 shows that consumers' resource constraints, measured by consumers' wage rate, are negatively associated with offline search $(\beta=-0.65,-0.48$ for dealer visits and print,

\footnotetext{
${ }^{6}$ As a reviewer suggested, another reason why users of resale web sites may be less likely to search dealer web sites is that dealers tend to list their offerings on resale web sites. This would limit the need to consult dealer sites.
} 
respectively), but positively associated with search on dealer websites $(\beta=0.91)$. Table 10 further shows that age has a strong positive relation to dealer visits $(\beta=0.48, \mathrm{E}=5.57)$ and search using traditional print $(\beta=0.42, \mathrm{E}=28.22)$. We find that older consumers are less likely to search online $(\beta=-0.82, \mathrm{E}=5.91 ;-0.39,-2.50$ for dealer and resale websites respectively). As noted above, we also find that word of mouth is positively associated with visiting dealers, and search on resale websites $(\beta=0.47,0.72$ respectively) and negatively associated with search on dealer websites $(\beta=-0.35)$. To interpret the relationships for dealer visits, it must be kept in mind that use of dealer websites is strongly related to dealer visits, and that use of dealer websites is also positively related to wages and inversely related to age and word of mouth (see Table 9). Thus dealer visits appear to be generated from two sources: younger, higher wage, consumers who use dealer websites, and older, lower wage, consumers who may rely on traditional print and word of mouth. This interpretation is consistent with findings in the literature on new car search.

\section{<Insert Table 10 here>}

As to other results in Table 10, consumers' experience with used cars does not have a significant relationship with offline or online information search. The number of models considered is positively associated with online search and negatively associated with offline search. ${ }^{7}$ This finding suggests that Internet offers higher convenience as well as efficiency gains to consumers considering a greater number of models. Another finding is that consumers' tendency to gather information is positively associated with search on dealer websites as well as resale websites $(\beta=0.27,0.46$ respectively) and negatively associated with search using traditional print $(\beta=-0.17)$. $^{8}$

\section{Choice of Seller Type}

As indicated by the model presented in Appendix B, consumers in our study are assumed to choose the mix of information sources that optimizes their gain from information. Thus their choice of information sources should be tailored to the seller type and car type that best fits their

\footnotetext{
${ }^{7}$ Number of models considered refers to the number of different makes and models considered for purchase. This measure does not account for the possibility that a buyer may search among many different cars of a given make and model.

${ }^{8}$ As the term implies, the key assumption is that the various exclusion restriction variables are uncorrelated with the error terms of the equations that they are excluded from, making them valid instruments in these equations. For example helpfulness of the dealer should be uncorrelated with the error term in the other three equations. Since the restriction variables pertain to specific sources, this assumption seems reasonable.
} 
needs. Observed choices of seller types should therefore be consistent with the search patterns found in this study. For example, those who use dealers and dealer web sites in their search should be more likely to buy at a dealer; those who rely on resale web sites should be more likely to buy from an independent seller. In this section we examine whether this is the case.

The choice of a specific seller type is called "seller choice" and is used as the dependent variable for this analysis. Using a logit choice model, the impact of information source use on seller choice is analyzed. Seller choice is measured as the seller type from which the most recent used car has been purchased. It is coded as 1 if the used car was purchased from a new car dealer, 2 if purchased from a used car dealer, 3 if purchased from a used car superstore, and 4 if purchased from an individual. Purchase from an individual seller is used as the base category.

The explanatory variables are the depth of search on offline and online sources. We control for seller trustworthiness and for the demographic characteristics of the buyers. The demographic characteristics are incorporated by interacting them with the choice dummy variable. Trustworthiness is specific to a seller and measured as competency of the seller, ability of the seller to deliver its promise, quality of cars, dependability and concern about customers. These variables have been measured on 5-point Likert scales based on Bruner et al. (1996).

The results are presented in Table 11. The results show that those who buy from independent sellers are more likely than others to use resale websites, and. less likely to make dealer visits. Those who buy from individual sellers also tend to be younger, consider more models, and to buy cheaper cars. These findings are consistent with our conjecture those who use resale web sites tend to be looking for in inexpensive car from an individual seller, and are not interested in dealer sources, possibly because dealers sell more expensive cars (see Table 11).

\section{<Insert Table 11>}

Conversely, those who buy from dealers tend to visit more dealers, buy more expensive cars, and to be older than those who buy from individual sellers. Except for superstores, they tend to consider fewer distinct makes and models than those who buy from individual sellers; since superstores sell a wide variety of cars, they make it easy to search for a variety of makes and models. Those who buy from superstores and used car dealers tend to have a lower wage than those who buy from individual sellers, even though these dealer customers tend to buy more 
expensive cars. Possibly they do not trust individual sellers. Finally use of dealer (retail) web sites does not appear to have a significant relation to buying from a given dealer type. ${ }^{9}$

\section{Conclusions}

In this study we investigate online and offline search in used durables markets, specifically the market for used cars. Prior research, in the context of new automobile purchases, finds that online search substitutes for offline search, with the greatest impact being on dealer visits. This literature does not distinguish between search on dealer websites and search on resale websites. However, the latter are typical for used markets, and are widely used by consumers.

The information sources in this study are grouped into dealer visit, print, dealer websites, and resale websites. Search on manufacturer websites is grouped together with search on dealer websites because manufacturer websites typically route consumers to dealer websites for used car listings. Resale websites include newspaper websites, auction websites, third party websites and local community websites. Resale websites are used by consumers to contact different dealer types directly or indirectly to request price quotes.

How does search on dealer and resale websites affect offline search? Based on the existing studies of search in different sources, we formulate several hypotheses. We develop and estimate a simultaneous equations Tobit model using survey data. In addition, we explore the choice of seller type using a conditional logit model.

The results show that for used cars, dealer websites are complementary to dealer visits. In contrast, many prior studies on new car search have found them to be substitutes. Search on resale websites, however, is a substitute for dealer visits. In the online medium, dealer websites and resale websites have an asymmetric association. Conversely dealer visit and print are substitutes to each other. For consumer characteristics such as age, wage and number of models considered, the direction of association on search differs in the online and offline medium.

The findings of this study have practical implications for dealers. Prior studies looked at the impact of the Internet's entry on search in traditional sources. The present study highlights the significance of disaggregate Internet sources, specifically the importance of web presence for dealers. Consumers who gather information, engage in price comparison, consider more makes and models and consult word of mouth are likely to search online. Dealers can facilitate

\footnotetext{
${ }^{9}$ The relation between dealer web sites and buying from a used car dealer is is significant at the $10 \%$ level.
} 
information gathering activity by providing information, such as on inspection and maintenance as well as online reviews and recommendations of used cars. Dealers can emphasize dynamic updating of online inventory to increase its reliability for consumers. Dealers can offer incentives or online specials to encourage consumers using resale websites to buy from dealers and not individual sellers.

Second, our study finds that word of mouth is positively associated with search for used cars on dealer lots. This suggests that prior customers may be a source of directing consumers to buy from dealers. On the other hand, word of mouth is negatively associated with search for used cars on dealer websites. This implies that dealers need to generate website traffic by employing social media marketing tools and generating positive publicity through blogs of opinion leaders. Dealers should emphasize high standards of customer service to get positive word of mouth.

Third, dealers can target customers based on consumer demographics and information source use. Those who purchase from a dealer appear to fall into two groups: younger buyers who focus their search on the web, who do not use word of mouth extensively, and have a high wage; older consumers who rely extensively on dealer visits and word of mouth, and have a lower wage.

Our analysis also suggests that time constrained (higher wage) individuals are more likely to search on dealer websites, make fewer dealer visits, and buy either from new car dealers or individual sellers. If they buy in a higher price range, they are more likely to buy from a dealer. These findings are broadly consistent with earlier results that indicate that time constrained consumers tend to search less and buy high quality brands (Nowlis 1995; Putrevu and Ratchford 1997). The general conclusion is that new car dealers can target their relatively high quality, high price offerings at older buyers who may not search extensively online unless they have a high income. The latter underscores the need to have an effective web site, as does the general relationship between dealer website use and dealer visits. Older consumers are relatively less experienced with using the Internet for tasks such as car shopping, compared to being more experienced with traditional sources. However, an implication is that as each new cohort of consumers ages, they will be more Internet savvy, which suggests that dealers should continue to maintain a robust online presence. At the same time, dealer websites can be made friendlier for older consumers, such as giving the option to get in touch with a consumer specialist if any questions or confusion should arise. 
Finally, our results also indicate how individual sellers can target their offerings. Those who buy from an individual seller tend to be younger, buy in a lower price range, consider more models, and use resale web sites. In turn, users of resale web sites also tend to use word of mouth and other sources, with the exception of dealer visits. The latter suggests dealers and individual sellers do not generally compete directly. Individual sellers are well advised to post their offerings on resale web sites frequented by younger prospects.

\section{Limitations \& Future Research}

This study is an initial empirical investigation of information search in the used car market on cross sectional data. It is subject to the limitations of cross sectional data as a vehicle for drawing causal inferences. For example, it is possible that the number of models considered and helpfulness variables are a function of information search rather than a predictor of it, instruments might not be uncorrelated with the error terms of equations from which they are excluded, common method bias may be present, or the model may be misspecified in some other way. Moreover the cross sectional design precludes a detailed examination of heterogeneity, and we have no information on the order in which the various information sources were consulted. Our results need to be interpreted with these possible limitations in mind, and further research that addresses them would be useful. In particular, an attempt to track a panel of potential buyers as they proceed through their search along the lines of Erdem, et al. (2005) might resolve some of the problems noted above. For example, such panel data would make it possible to examine possible lead-lag relationships in the search process (Pierce and Haugh 1977), providing evidence of temporal precedence as a basis for making causal inferences. The challenge in setting up such a panel rests with identifying a sample of prospective buyers who are early in their process of searching for a used car. 


\section{Appendix A. Survey of Used Car Buyers (2010)}

1. Where was the car listed/located?

[ ] Newspaper (print) $\quad$ [ ] Website (Please specify the name__
[ ] Dealer Visit [ ] Other (Please specify__

2. Please provide the following information about your recently purchased used car.

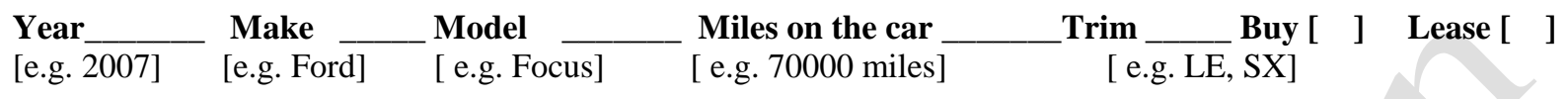

3. Did you buy/lease car from:

[ ] Individual (unknown) owner [ ] Family member/friends/relatives [ ] Colleague

[ ] Used car superstore [ ] New Car dealer [ ] Used Car Dealer

Please mention Dealer/superstore name (if applicable)

1. When you first seriously thought about purchasing your recent used car:

i. Did you know which specific make and model you wanted to buy?

[ ] Definitely Yes [ ] Was not sure [ ] Definitely No

ii. Did you know which specific seller you wanted to buy from?

[ ] Definitely Yes [ ] Was not sure [ ] Definitely No

iii. Were you interested in collecting information on what make and model to buy?
[ ] Extremely Interested
[ ] Somewhat Interested
[ ] Not Interested

iv. Were you interested in information on best price of a particular car?
[ ] Extremely Interested
[ ] Somewhat Interested
[ ] Not Interested

2. Please number the following options in the order in which you searched for your recent used car.(i.e. 1,2,3)

(i) I searched to narrow down makes and models considered [ ]

(ii) I searched for used cars from the models that I selected [ ]

(iii) I evaluated the selected cars and chose one [ ]

(iv) Please specify if you searched in any other way

3. Which makes and models did you seriously consider for purchase and in what price range? (Please list them below).

\section{Make}

EXAMPLE: Honda

a.

b.

c. $\underline{\text { Model }}$

Accord

.

\author{
$\underline{\text { Approximate Price Range }}$
}

$\$ 2000-\$ 5000$ 
4. Can you tell us how much time you allocated to the following activities and how helpful was each activity in searching for information? (Please write the approximate time spent in hours and minutes for activities that apply.)

Rating Scale

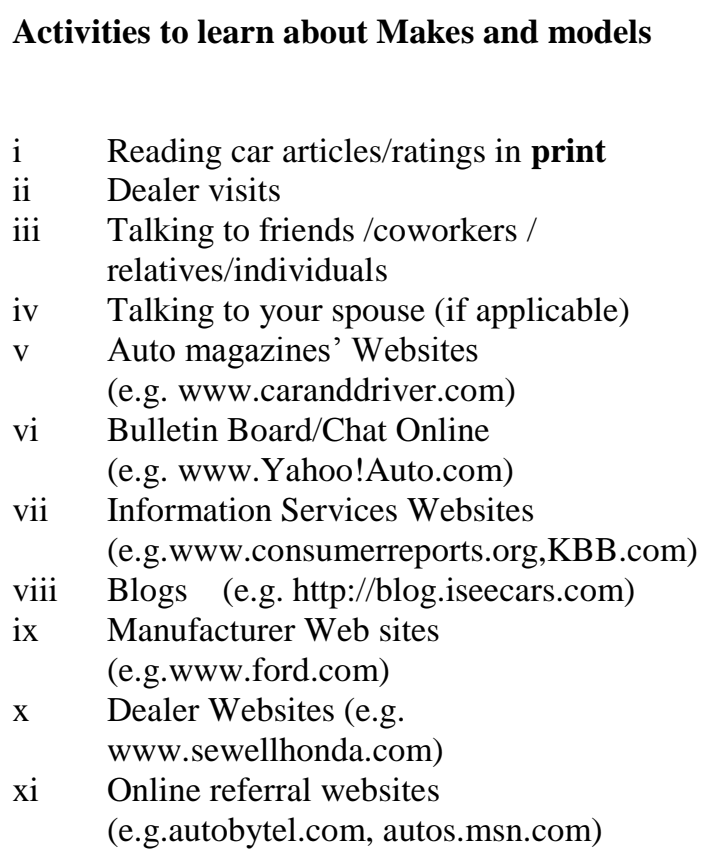

Activities to find/locate used cars for purchase

i Reading newspapers in print

ii Newspaper websites

iii Classified advertisements

iv Through

friends/coworkers/relatives/individuals

v Dealer Visits

vi Manufacturer Web sites (e.g. www.ford.com)

vii Dealer Websites (e.g. www.dallasdodge.net)

viii Used car superstore websites (e.g.carmax.com)

ix Online referral websites (e.g. autobytel.com)

$\mathrm{x} \quad$ Third party websites (e.g. www.cars.com,KBB )

xi Auction websites (e.g. www.ebay.com)

xii Local websites (e.g. www.craigslistdallas.com)

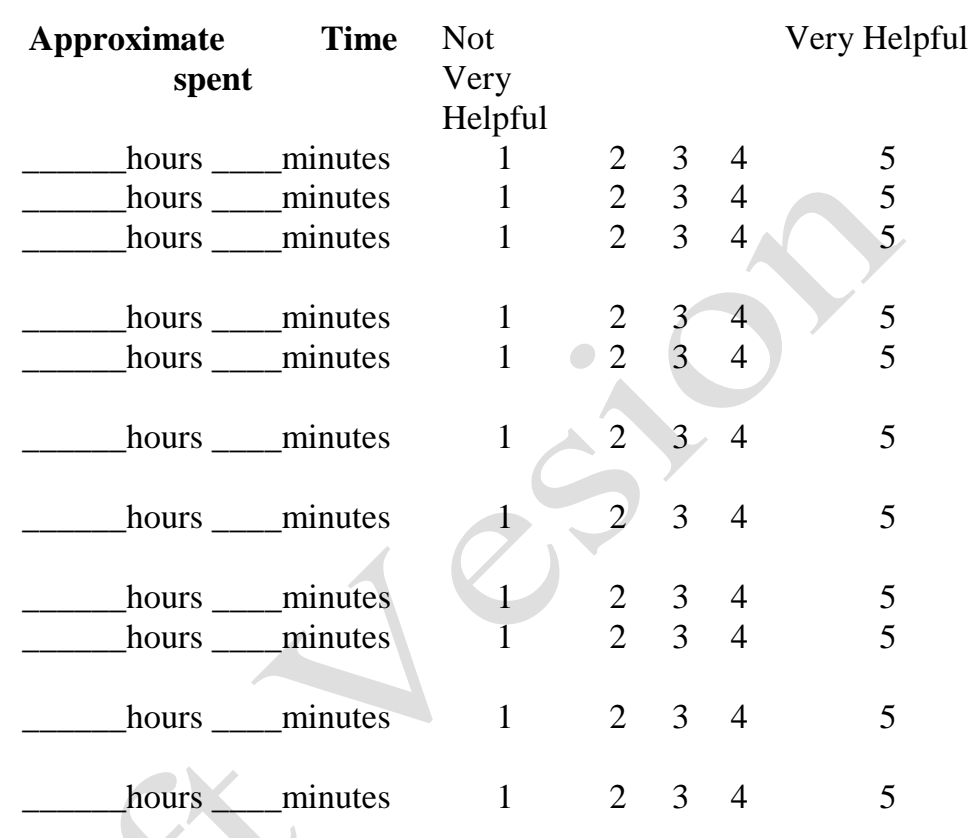

$\underline{\text { Rating Scale }}$




5. Please tell us the number of different sources that you personally checked to find used cars from each of the following sources? (Please circle one number for the type of source consulted.)

Websites

Newspapers websites
(e.g. www.dallasnews.com)
Manufacturer websites (e.g. www.Ford.com)
Dealer websites (e.g. www.dallasdodge.net)
Used car superstore websites (e.g.
carmax.com)
Online referral websites (e.g.
www.autos.msn.com)
Third party websites (e.g. www.cars.com)
Auction websites (e.g. www.ebay.com)
Local websites (e.g. www.craigslistdallas.com)

\section{$\underline{\text { Print }}$}

Newspapers in print
Number of different websites visited

$\begin{array}{lllllllllllll}0 & 1 & 2 & 3 & 4 & 5 & 6 & 7 & 8 & 9 & 10 & \text { More than } 10 \text { (Please specify__ } \\ 0 & 1 & 2 & 3 & 4 & 5 & 6 & 7 & 8 & 9 & 10 & \text { More than } 10 \text { (Please specify__ } \\ 0 & 1 & 2 & 3 & 4 & 5 & 6 & 7 & 8 & 9 & 10 & \text { More than } 10 \text { (Please specify__ } \\ 0 & 1 & 2 & 3 & 4 & 5 & 6 & 7 & 8 & 9 & 10 & \text { More than } 10 \text { (Please specify__ } \\ 0 & 1 & 2 & 3 & 4 & 5 & 6 & 7 & 8 & 9 & 10 & \text { More than } 10 \text { (Please specify__ } \\ 0 & 1 & 2 & 3 & 4 & 5 & 6 & 7 & 8 & 9 & 10 & \text { More than } 10 \text { (Please specify__ } \\ 0 & 1 & 2 & 3 & 4 & 5 & 6 & 7 & 8 & 9 & 10 & \text { More than } 10 \text { (Please specify_) } \\ 0 & 1 & 2 & 3 & 4 & 5 & 6 & 7 & 8 & 9 & 10 & \text { More than } 10 \text { (Please specify__ }\end{array}$

Number of different Newspapers

$\begin{array}{llllllllllll}0 & 1 & 2 & 3 & 4 & 5 & 6 & 7 & 8 & 9 & 10 & \text { More than } 10 \text { (Please specify }\end{array}$

6. Please tell us how you feel about the following statements related to your shopping experience:

\begin{tabular}{|c|c|c|c|c|c|c|}
\hline & & $\begin{array}{l}\text { Strongly } \\
\text { Disagree }\end{array}$ & & & & $\begin{array}{l}\text { Strongly } \\
\text { Agree }\end{array}$ \\
\hline i. & I frequently use internet to obtain information about products I am interested in. & 1 & 2 & 3 & 4 & 5 \\
\hline ii. & I enjoy visiting stores before I make a purchase. & 1 & 2 & 3 & 4 & 5 \\
\hline iii. & I really enjoy talking to salespeople before I make a purchase. & 1 & 2 & 3 & 4 & 5 \\
\hline iv. & I do a lot of price comparison when making larger purchases. & 1 & 2 & 3 & 4 & 5 \\
\hline v. & I read car enthusiast magazines regularly. & 1 & 2 & 3 & 4 & 5 \\
\hline vi & I like to gather as much information as possible before I visit car dealers. & 1 & 2 & 3 & 4 & 5 \\
\hline $\mathrm{vi}$ & Overall I really enjoy shopping before I make a purchase. & 1 & 2 & 3 & 4 & 5 \\
\hline
\end{tabular}

7. Do you have internet access at (i) WORKPLACE [ ] Yes [ ] No (ii) HOME /PUBLIC PLACE [ ]Yes [ ] No

8. What is your age? [ ] 20 years or younger [ ] 31 to 40 years [ ]51-60 years
[ ] 21 to 30 years
[ ] 41-50 year
[ ] more than 60 years

12. Number of years of formal education that you have completed.

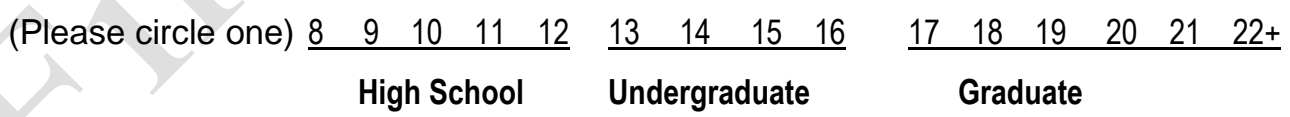

13. Number of children presently in your household. (Include only those in your house.)

14. Total number of cars in your household at present (including your recent used car).

15. Number of years that you have lived in the area of your current residence (e.g. City of Plano).

16. What is your approximate hourly wage?
Please check one [ ] None [ ] $\$ 5-\$ 10$ [ ] $\$ 16-\$ 20$ [ ] $\$ 26-\$ 30$ [ ] $\$ 51-\$ 70$
[ ] Under $\$ 5$ [ ] $\$ 11-\$ 15$ [ ] $\$ 21-\$ 25$ [ ] $\$ 31-\$ 50$ [ ] Above $\$ 70$

Note: The complete survey questionnaire is available from the authors upon request. 


\section{Appendix B. Derivation of Empirical Model}

As noted in the literature review, existing models of the choice of information sources do not readily accommodate complementarity. However, in this appendix we will show that the model employed in estimation in this study can readily be derived from the framework presented in Ratchford, Lee and Talukdar (2003) - hereafter RLT. In the model of RLT, a consumer allocates time $t$ among $J$ sources to maximize the expected gain to search in the face of a cost per unit of time, $w$. The expected gain to search is the product of the maximum possible gain, $g$, and the fraction of the maximum that is produced by the time allocation, $I$. Since $I$ varies between 0 and 1 , it is represented by a function that is restricted to this range, and exhibits diminishing returns: $I=1-e^{-(S+F)}$, where $S$ represents prior information and $F$ is a function relating time with each source to $I$. RLT define $F=\sum_{j} a_{j} \ln \left(t_{j}\right)$, where $t_{j}$ is time allocated to source $j$, and $a_{j}$ is a weight reflecting the productivity of the source. Putting these components together leads to the following maximization problem:

$$
\max _{t_{1}, \ldots, t_{J}} g I-w \sum_{j} t_{j}=\max _{t_{1}, \ldots, t_{J}} g\left(1-e^{-\left[S+\sum_{j} a_{j} \ln \left(t_{j}\right)\right]}\right)-w \sum_{j} t_{j} .
$$

While this model has a particularly simple solution in which the share of each source is equal to its relative productivity, $t_{j} / \sum_{j} t_{j}=a_{j} / \sum_{j} a_{j}$, it has the IIA property, and, because of the separable form of $F$, does not accommodate complements.

A model that does accommodate complements can readily be adapted to the above framework if $F$ is defined with interaction terms. As it eliminates problems of dealing with $\log$ of zero being undefined, we adopt a linear-quadratic form, $F=\sum_{j} a_{j} y_{j}-(1 / 2) \sum_{j} \sum_{k} b_{j k} y_{j} y_{k} \cdot{ }^{10}$ Here we use $y_{j}$ instead of $t_{j}$ to reflect the fact that the consumer's allocation problem is to allocate numbers of sources of a given type, $y_{j}$, rather than time. The cost of accessing a source is now $w_{j}$, allowing it to vary across sources (accessing a dealer is likely to be much more expensive than accessing the dealer's web site). Finally we add Lagrange multipliers to represent the constraint that $y_{j}$ is nonnegative. Given these modifications the counterpart to Equation 1 becomes: ${ }^{11}$

\footnotetext{
${ }^{10}$ Subtracting the quadratic term requires that the coefficients $b_{j j}$ of the $y_{j}^{2}$ terms be positive.

${ }^{11}$ We suppress a subscript to represent consumer to simplify notation. However it should be understood that this is a model of an individual consumer.
} 
$\max g I-\sum_{j} w_{j} y_{j}+\sum_{j} \lambda_{j} y_{j}=\max g\left(1-e^{-\left(S+\sum_{j} a_{j} y_{j}-(1 / 2) \sum_{j} \sum_{k} b_{j k} y_{j} y_{k}\right)}\right)-\sum_{j}\left(w_{j}-\lambda_{j}\right) y_{j}$.

Assume for simplicity that the coefficients of the quadratic terms are symmetric, i.e., $b_{j k}=b_{k j}$. Differentiating with respect to each $y_{j}$ gives a set of $J$ first-order conditions of the form:

$$
g e^{-(S+F)}\left(a_{j}-\sum_{k} b_{j k} y_{k}\right)-w_{j}+\lambda_{j}=0
$$

Differentiating with respect to each $\lambda_{j}$ gives another set of $J$ first-order conditions of the form $y_{j}=0$, which must be the case if $\lambda_{j}$ is nonzero.

Denote the gains realized from search as $g^{*} \equiv g\left(1-e^{-(S+F)}\right)$, which implies that $g e^{-(S+F)}=g-g *$, the difference between the maximum possible gain, $g$, and the actual gain, $g *$. One of the $b_{j k}$ terms in Equation B3 must be set to a constant to identify the model. We scale the coefficient of the derivative of the quadratic term to one by dividing both sides of Equation B3 by $b_{j j}$. After doing this, substituting $g-g *$ for $g e^{-(S+F)}$ and rearranging terms, we get a modified version of Equation B3:

$$
y_{j}+\sum_{k \neq j}\left(\frac{b_{j k}}{b_{j j}}\right) y_{j}=\frac{1}{b_{j j}}\left(\frac{\lambda_{j}-w_{j}}{g-g *}+a_{j}\right)
$$

In the absence of the interaction terms in $F$, the $y_{i}$ terms would disappear and a single equation would suffice to describe the demand for a given source. Existence of the interaction terms means that the entire system of $J$ equations has to be solved. ${ }^{12}$ Define $\Gamma$ as a $J \times J$ matrix of coefficients, with one in the diagonal and $b_{j k} / b_{j j}$ on the off-diagonals, $Y$ as a $J \times 1$ vector with elements $y_{j}, \mathrm{~A}$ as a $J \times 1$ vector with elements $a_{j}, \lambda$ as a $J \times 1$ vector with elements $\lambda_{j} / b_{j j}$, and $W$ as a $J \times 1$ vector with elements $w_{j} / b_{j j}$. Then the $J$ first order conditions in Equation 4 can be expressed in matrix form as,

$$
\Gamma Y=\mathrm{A}+(\lambda-W) /\left(g-g^{*}\right) .
$$

This defines the maximum when second order conditions are fulfilled, which requires the $b_{j j}$ terms to be positive, and the determinant of $\Gamma$ be positive definite. An alternative way to express Equation 5 is as a system of $J$ equations with each $y_{j}$ as a dependent variable:

$$
Y=-(\Gamma-\mathrm{I}) Y+\mathrm{A}+(\lambda-W) /\left(g-g^{*}\right)
$$


where the matrix $\Gamma-\mathrm{I}$ has zeros in the diagonal.

The vectors A and $W /\left(g-g^{*}\right)$ should vary across the sample with consumer characteristics. A should vary with factors associated with increased efficiency of using a source, such as perceptions of its helpfulness, experience, and enjoyment. The efficiency of using online sources should increase with Internet use. Since it is related to experience, the efficiency of using some sources might increase with age. However, to the extent that older people are less adept at using technology, the efficiency of using online sources might decrease with age. $W$ should vary with factors related to search costs. While $g-g *$ should decrease with prior information, it might also be related to experience and age. Such decreases should lessen search. However, we argued earlier that prior information might not be useful for many aspects of search for used cars, such as locating and inspecting currently available models. In sum, A and $W /\left(g-g^{*}\right)$ should vary cross-sectionally with relevant consumer characteristics:

$$
\mathrm{A}_{i}-W_{i} /\left(g_{i}-g_{i}^{*}\right)=X_{i}^{*} \beta+\varepsilon_{i}
$$

where the subscript $i$ refers to consumer, $X_{i}^{*}$ denotes consumer characteristics, $\beta$ is a matrix of regression coefficients, and $\varepsilon_{i}$ is a random error term. Substituting Equation B7 into B5, and rearranging gives:

$$
\Gamma Y_{i}=\lambda_{i}+X_{i}^{*} \beta+\varepsilon_{i}
$$

For elements of $Y_{i}$ that are $>0$, the corresponding element of $\lambda_{i}=0$. However for elements of $Y_{i}$ that are zero, there is a corner solution and the corresponding element of $\lambda_{i}$ is a latent variable that removes the inequality produced by the corner solution. Accordingly, we define the relationship between consumers' latent search on source $j$ and the observed depth of search using source $j$ as:

$$
y_{i j}=\left\{\begin{array}{lll}
y_{i j}^{*} & \text { if } & y_{i j}^{*}>0, \\
0 & \text { if } & y_{i j}^{*} \leq 0 .
\end{array}\right.
$$

Define the vector of latent elements $y_{i j}^{*}$ as $Y_{i}^{*}$. Then consumer $i$ 's use of $J$ sources can be expressed in matrix form as:

$$
\Gamma Y_{i}^{*}=X_{i}^{*} \beta+\varepsilon_{i}
$$

or equivalently as:

$$
Y_{i}^{*}=-(\Gamma-\mathrm{I}) Y_{i}^{*}+X_{i}^{*} \beta+\varepsilon_{i}
$$


Equations B9-B11 are Equations 1-3 in the text. To derive Equation 4 in the text from B11, we define $\gamma_{j k}=-b_{j k} / b_{j j}$. Because of the normalization by $b_{j j}$ generally $\gamma_{j k} \neq \gamma_{k j}$. 


\section{References}

Akerlof, George A. (1970), “The Market for 'Lemons': Quality Uncertainty and the Market Mechanism," Quarterly Journal of Economics, 84 (3), 488-500.

Albert, Jim and Siddhartha Chib (1996), "Computation in Bayesian Econometrics: An Introduction to Markov Chain Monte Carlo," Advances in Econometrics, 11(A), 3-24.

Antonakis, John, Samuel Bendahan, Philippe Jacquart, and Rafael Lalive (2010), “On making Causal Claims: A Review and Recommendations," Leadership Quarterly, 21(6), 10861120.

Bakos Yannis (1998), "The Emerging Role of Electronic Marketplaces on the Internet," Communications of the ACM, 41(8), 35-42.

Bruner, Gordon C., Paul J. Hensel and Karen E. James (1996). Marketing Scales Handbook: A Compilation of Multi-item Measures, Vol. 2, Chicago: AMA.

Chen, Kay-Yut, Murat Kaya and Özalp Özer (2008), "Dual Sales Channel Management with Service Competition," Manufacturing and Service Operations Management, 10(4), 654675.

Cameron, Colin A. and Pravin K. Trivedi (2005), Microeconometrics: Methods and Applications, NY: Cambridge University Press.

Chib, Siddhartha (1992), "Bayesian Inference in the Tobit Censored Regression Model," Journal of Econometrics, 51, 79-90.

Dowling G. R. and Richard Staelin (1994), "A Model of Perceived Risk and Intended RiskHandling Activity," Journal of Consumer Research, 21(1), 119-134.

Erdem, Tulin, Michael P. Keane, T. Sabri Öncü and Judi Strebel (2005), "Learning about computers: An analysis of information search and technology choice," Quantitative Marketing and Economics, 3(3), 207-247.

Furse, David H., Girish N. Punj and David W. Stewart (1984), “A Typology of Individual Search Strategies among Purchasers of New Automobiles," Journal of Consumer Research, 10(4), 417-431.

Gelfand, Alan E., Adrian F. M. Smith and Tai-Ming Lee (1992), "Bayesian Analysis of Constrained Parameter and Truncated Data Problems using Gibbs Sampling," Journal of the American Statistical Association, 87(418), 523-532.

Grewal, Dhruv, Gopalkrishnan R. Iyer, Radha Krishnan and Arun Sharma (2003), "The Internet and the Price-Value-Loyalty chain," Journal of Business Research, 56 (5), 391-398.

Heckman, James J., and Edward J. Vytlacil (2007), "Econometric evaluation of social programs, part I: Causal models, structural models and econometric policy evaluation," Handbook of Econometrics 6, 4779-4874. (2008), "Econometric causality," International Statistical Review, 76(1),1-27.

Jang, Sungha, Ashutosh Prasad and Brian T. Ratchford (2010), “Consumer Spending Patterns across Firms and Categories: Application to the Size and Share of Wallet," UT Dallas working paper. 
Kim, Jung Seek and Brian T. Ratchford (2012), "Consumer Choice and Use of Multiple Information Sources for Automobile Purchases," International Journal of Electronic Commerce, 16(3), 7-40.

Klein, Lisa R. and Gary T. Ford (2003), "Consumer search for Information in the Digital Age: An Empirical Study of Prepurchase Search for Automobiles," Journal of Interactive Marketing, 17(3), 29-49.

Koop, Gary (2003). Bayesian Econometrics, Hoboken, NJ: Wiley.

Kukar-Kinney, Monika, Nancy M. Ridgway and Kent B. Monroe (2009), "The relationship between Consumers' Tendencies to Buy Compulsively and their Motivations to Shop and Buy on the Internet," Journal of Retailing, 85(9), 298-307.

Li, Kai (1998), "Bayesian Inference in a Simultaneous Equation Model with Limited Dependent Variables," Journal of Econometrics, 85, 387-400.

Long, J. Scott (1997). Regression Models for Categorical and Limited Dependent Variables, Vol.7, Thousand Oaks, CA: Sage Publications.

Moorthy, Sridhar, Brian T. Ratchford and Debabrata Talukdar (1997), "Consumer Information Search Revisited: Theory and Empirical Analysis," Journal of Consumer Research, 23(4), 263-277.

Nowlis, Stephen M (1995), "The Effect of Time Pressure on the Choice between Brands that Differ in Quality, Price, and Product Features," Marketing Letters, 6(4), 287-295.

Pauwels, Koen, Peter S.H. Leeflang, Marije L. Teerling and K.R. Huizing (2011), "Does Online Information drive Offline Revenues? Only for specific Products and Customer Segments!" Journal of Retailing, 87(1), 1-17.

Pierce, David A. and Larry D. Haugh (1977), "Causality in Temporal Systems: Characterizations and a Survey," Journal of Econometrics, 5, 265-293.

Punj, G. J. and R. Staelin (1983), "A Model of Consumer Information Search Behavior for New Automobiles," Journal of Consumer Research, 9(4), 366-80.

Putrevu, Sanjay and Brian T. Ratchford (1997), "A Model of Search Behavior with an Application to Grocery Shopping," Journal of Retailing, 73(4), 463-486.

Ratchford, Brian T. and Narasimhan Srinivasan (1993), "An Empirical Investigation of Returns to Search," Marketing Science, 12(1), 73-87.

, Debabrata Talukdar and M. Lee (2001), "A Model of Consumer Choice of the Internet as an Information Source," International Journal of Electronic Commerce, 5(3), 7-21.

, Myung-Soo Lee and Debabrata Talukdar (2003), "Impact of the Internet on Information Search for Automobiles," Journal of Marketing Research, 40(2), 193-209. , Debabrata Talukdar and Myung-Soo Lee (2007), "The impact of the Internet on Consumers' use of Information Sources for Automobiles," Journal of Consumer Research, 34(1), 111-119.

- (2008), "Consumer Search Behavior and its Effect on Markets," Foundations and Trends in Marketing, 3(1), 1-74. 
Sarvary, Miklos and Philip M. Parker (1997), "Marketing information: A competitive analysis." Marketing Science, 16(1), 24-38.

Srinivasan, Narasimhan and Brian T. Ratchford (1991), "An Empirical Test of a Model of External Search for Automobiles," Journal of Consumer Research, 18(2), 233-242.

Stone, Robert N. and Kjell Grønhaug (1993) "Perceived Risk: Further Considerations for the Marketing Discipline," European Journal of Marketing, 27(3), 39-50.

Tanner, Martin A. and Wing Huang Wong (1987), "The Calculation of Posterior Distributions by Data Augmentation," Journal of the American Statistical Association 82(398), 528-500.

Yang, Sha, Vishal Narayan and Henry Assael (2006), "Estimating the interdependence of television program viewership between spouses: A Bayesian simultaneous equation model," Marketing Science, 25(4), 336-349.

Zellner, Arnold (1996), Introduction to Bayesian Inference in Econometrics, New York: Wiley. Zettelmeyer F., F.M. Morton and Jorge Silva-Risso (2006), "How the Internet Lowers Prices: Evidence from Matched Survey and Automobile Transaction Data," Journal of Marketing Research, 43, 168-181. 
Table 1

Literature Review

Literature $\quad$ Findings

Search Offline

Furse et al. 1984

Srinivasan \&Ratchford 1991

Moorthy et al. 1997

Hauser et al. 1993

- Size of the feasible set impacts search.

- Inverted U shaped relation between knowledge and search.

- Examine consumers' allocation of time and find the value of an information source.

\section{Search Offline or one Online Medium}

Klein \& Ford 2003

Ratchford et al. 2003

Ratchford et al. 2007.

Pauwels et al. 2011
Examine the impact of Internet on search:

- Internet substitutes for offline search.

- Website presence and (non- price) online communications improve offline revenue performance more for sensory products.

\section{Search Offline or
Present Study}

Multiple Online Media

Examines disaggregate impact of online search:

- Search on resale websites substitutes for offline search.

- Search on dealer websites complements offline search. 
Table 2

Comparison of New and Used Car Markets

\begin{tabular}{|c|c|c|}
\hline New Car Market & Used Car Market & Search Implications \\
\hline \multicolumn{3}{|l|}{ Market Characteristics } \\
\hline $\begin{array}{l}\text { Current year makes and } \\
\text { models } \\
\text { One seller type in the market: } \\
\text { (Franchised dealers) } \\
\text { Availability is less uncertain. }\end{array}$ & $\begin{array}{l}\text { Greater variety of makes and } \\
\text { models and vintages. } \\
\text { Several seller types: } \\
\text { (Franchised dealers, Non- } \\
\text { franchised dealers, } \\
\text { Individual resellers) } \\
\text { Availability is uncertain. }\end{array}$ & $\begin{array}{l}\text { The need to locate information } \\
\text { about the availability of } \\
\text { different makes, models, and } \\
\text { vintages from different seller } \\
\text { types implies the use of } \\
\text { multiple information sources. }\end{array}$ \\
\hline \multicolumn{3}{|l|}{ Product Characteristics } \\
\hline $\begin{array}{l}\text { Quality of new cars is more } \\
\text { certain and there is greater } \\
\text { protection from buying a } \\
\text { lemon. } \\
\text { New car prices are higher }\end{array}$ & $\begin{array}{l}\text { Quality of used cars for the } \\
\text { same make and model } \\
\text { differs across sellers. } \\
\text { Classical information } \\
\text { asymmetry problem faced } \\
\text { by buyers and sellers. }\end{array}$ & $\begin{array}{l}\text { Buyers in new car markets only } \\
\text { need to settle on a make, } \\
\text { model and price. Buyers in } \\
\text { used car markets need to do } \\
\text { this, and, in addition, to } \\
\text { distinguish quality differences } \\
\text { between cars of a given make } \\
\text { and model. In particular, they } \\
\text { need to address the } \\
\text { information asymmetry by } \\
\text { efforts to verify the quality of } \\
\text { car and seller. The added } \\
\text { information needs imply more } \\
\text { search for suitable cars and } \\
\text { sellers in used markets. }\end{array}$ \\
\hline \multicolumn{3}{|l|}{ Seller Characteristics } \\
\hline $\begin{array}{l}\text { New car dealers should be } \\
\text { more trustworthy than used } \\
\text { car dealers due to franchise } \\
\text { requirements and volume of } \\
\text { sales. }\end{array}$ & $\begin{array}{l}\text { Used car salespeople have a } \\
\text { notably poor reputation, } \\
\text { while individual sellers } \\
\text { may have no reputation. }\end{array}$ & $\begin{array}{l}\text { With used cars, buyers may do } \\
\text { greater seller and product } \\
\text { background search and obtain } \\
\text { information from other } \\
\text { sources than dealer visits. }\end{array}$ \\
\hline \multicolumn{3}{|l|}{ Buyer Characteristics } \\
\hline $\begin{array}{l}\text { Buyers may be less price } \\
\text { sensitive, have higher } \\
\text { opportunity cost of time and } \\
\text { seek more convenience. }\end{array}$ & $\begin{array}{l}\text { Buyers may be price } \\
\text { sensitive, have lower } \\
\text { opportunity costs of time. }\end{array}$ & $\begin{array}{l}\text { The differences suggest more } \\
\text { search in the used car market. }\end{array}$ \\
\hline \multicolumn{3}{|l|}{ Source Characteristics } \\
\hline $\begin{array}{l}\text { Due to less uncertainty, } \\
\text { sources are likely to be } \\
\text { reliable but also to contain } \\
\text { overlapping information. }\end{array}$ & $\begin{array}{l}\text { Due to greater variety in } \\
\text { availability of cars and } \\
\text { seller types, each source is } \\
\text { less comprehensive, more } \\
\text { independent, but less } \\
\text { reliable. }\end{array}$ & $\begin{array}{l}\text { Sources are more likely to be } \\
\text { complements (substitutes) } \\
\text { when they are less (more) } \\
\text { reliable and more (less) } \\
\text { independent. }\end{array}$ \\
\hline
\end{tabular}


Table 3

Descriptive statistics (Sample size N=239)

\begin{tabular}{|c|c|c|c|c|c|c|}
\hline Variables & Mean & SD & Min & Max & $\begin{array}{l}\text { RLT }^{\mathrm{a}} \\
(\mathbf{2 0 0 3})\end{array}$ & $\begin{array}{c}\text { RLT } \\
(2007)\end{array}$ \\
\hline Number of models considered & 2.39 & 1.03 & 1 & 4 & 2.72 & 2.71 \\
\hline Know specific make and model to buy & 0.33 & 0.47 & 0 & 1 & 0.48 & 0.54 \\
\hline Know specific seller to buy from & 0.17 & 0.38 & 0 & 1 & 0.27 & 0.36 \\
\hline First car bought & 0.27 & 0.44 & 0 & 1 & 0.04 & 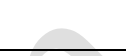 \\
\hline Satisfaction with previous car & 4.25 & 0.95 & 1 & 5 & 5.84 & 5.59 \\
\hline Satisfaction with previous seller & 4.13 & 1.10 & 1 & 5 & 5.50 & 5.39 \\
\hline Experience with used cars & 1.85 & 1.75 & 0 & 9 & & \\
\hline Experience with new cars & 0.51 & 0.93 & 0 & 5 & 1.54 & 2.34 \\
\hline Sticker price of car & $\$ 12477$ & $\$ 8500$ & $\$ 0$ & $\$ 55282$ & $\$ 21319$ & $\$ 24110$ \\
\hline Male & 0.67 & 0.47 & 0 & $1 \square$ & 0.52 & 0.57 \\
\hline Married & 0.64 & 0.48 & 0 & 1 & 0.66 & \\
\hline Years of formal education & 17.24 & 2.79 & 12 & 22 & 15.04 & 15.17 \\
\hline Number of children & 1.19 & 1.23 & 0 & 5 & 0.84 & \\
\hline Number of cars in the household & 2.16 & 0.95 & 0 & 8 & 1.97 & \\
\hline Numbers of years of living in the area & 10.64 & 10.17 & 1 & 53 & 25.70 & \\
\hline Age & 37.62 & 11.56 & 20 & 65 & 48.28 & \\
\hline Income & $\$ 74667$ & $\$ 41640$ & $\$ 2500$ & $\$ 150000$ & $\$ 59583$ & $\$ 64470$ \\
\hline Dollar wage & $\$ 33$ & $\$ 22$ & $\$ 7.5$ & $\$ 85$ & $\$ 22$ & $\$ 24.87$ \\
\hline Time spent consulting word of mouth & 1.24 & 2.73 & 0 & 24 & & \\
\hline Frequency of Internet Use & 4.37 & 1.08 & 1 & 5 & & \\
\hline Enjoy Store Visit & 3.29 & 1.25 & 1 & 5 & & \\
\hline Talking to salespeople & 2.50 & 1.23 & 1 & 5 & & \\
\hline Engage in price comparison & 4.39 & 0.93 & 1 & 5 & & \\
\hline Read car enthusiast magazines & 1.60 & 1.03 & 1 & 5 & & \\
\hline $\begin{array}{l}\text { Prefer to gather as much information } \\
\text { before visiting a dealer }\end{array}$ & 3.72 & 1.20 & 1 & 5 & & \\
\hline Number of dealers visited & $3.24^{\mathrm{b}}$ & 2.84 & 0 & 15 & & 2.19 \\
\hline Number of newspapers in print & 0.56 & 1.34 & 0 & 10 & & \\
\hline Number of dealer websites visited & 5.27 & 5.26 & 0 & 30 & 1.38 & 3.41 \\
\hline Number of resale websites visited & 5.86 & 8.23 & 0 & 50 & $2.52^{\mathrm{c}}$ & 2.151 \\
\hline
\end{tabular}

a refers to Ratchford, Lee and Talukdar study. (2003) study figures are for Year 1999; (2007) study figures are for Year 2002.

b-RLT(2003) do not report this number. Klein and Ford (2003) report that 39\% buyers visit 2 or fewer dealers.

c- RLT(2003) study reports the number of hybrid sources consulted which are comparable to resale websites. The hybrid sources refer to non-advocate sources such as Consumer reports, Edmonds, Kelly Blue Book, Autobytel etc. Note: Klein and Ford (2003) report search for early buyer, late buyers and shoppers and they use an aggregate measure for depth of search. Therefore, their sample statistics is not directly comparable to our sample. In their sample of 169 buyers, the average total search time is 35.14 hours and the median search time is 14 hours. In RLT (2003), the average total search time is 15.58 hours and median of total search time is 13.92 hours for a sample of 886 byers. In our sample of 239 buyers, the average total hours searched is 32.6 hours and median search time 23 hours respectively. 
Table 4

Correlation matrix

\begin{tabular}{|c|c|c|c|c|c|c|c|c|c|c|c|c|c|c|c|c|c|c|c|}
\hline & $1^{d}$ & 2 & 3 & 4 & 5 & 6 & 7 & 8 & 9 & 10 & 11 & 12 & 13 & 14 & 15 & 16 & 17 & 18 & 19 \\
\hline 1. DV & 1.00 & & & & & & & & & & & & & & 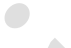 & & & & \\
\hline 2. PRINT & 0.07 & 1.00 & & & & & & & & & & & & & & & & & \\
\hline 3. DW & 0.40 & 0.39 & 1.00 & & & & & & & & & & & & & & & & \\
\hline 4. RW & 0.14 & 0.32 & 0.40 & 1.00 & & & & & & & & & & & & & & & \\
\hline 5. WOM & 0.07 & 0.16 & 0.02 & 0.25 & 1.00 & & & & & & & & & & & & & & \\
\hline 6. EUC & -0.02 & -0.04 & -0.09 & -0.05 & -0.03 & 1.00 & & & & & & & & & & & & & \\
\hline 7. WAGE & 0.05 & -0.03 & 0.07 & -0.05 & -0.13 & 0.03 & 1.00 & & & & & & & & & & & & \\
\hline 8. AGE & 0.08 & -0.05 & -0.16 & -0.15 & -0.10 & 0.19 & 0.15 & 1.00 & & & & & & & & & & & \\
\hline 9.MODELS & 0.24 & -0.02 & 0.23 & 0.22 & 0.07 & -0.10 & 0.03 & -0.09 & 1.00 & & & & & & & & & & \\
\hline 10. HDV & 0.28 & -0.03 & 0.17 & -0.21 & -0.08 & -0.07 & 0.11 & 0.12 & -0.05 & 1.00 & & & & & & & & & \\
\hline 11.HPRINT & 0.02 & 0.41 & 0.06 & 0.10 & 0.04 & -0.08 & -0.03 & 0.02 & -0.08 & -0.07 & 1.00 & & & & & & & & \\
\hline 12. HDW & 0.21 & 0.21 & 0.68 & 0.17 & -0.07 & -0.04 & 0.09 & -0.18 & 0.15 & 0.25 & 0.03 & 1.00 & & & & & & & \\
\hline 13. HRW & 0.03 & 0.21 & 0.29 & 0.63 & 0.10 & -0.08 & -0.01 & -0.19 & 0.28 & -0.28 & 0.07 & 0.20 & 1.00 & & & & & & \\
\hline 14. D11 & 0.07 & -0.03 & 0.21 & 0.13 & 0.03 & -0.05 & 0.08 & -0.29 & 0.22 & -0.01 & -0.18 & 0.26 & 0.24 & 1.00 & & & & & \\
\hline 15. D12 & 0.09 & 0.02 & 0.12 & 0.02 & 0.07 & -0.05 & -0.05 & 0.02 & 0.00 & 0.23 & 0.07 & 0.15 & 0.02 & 0.03 & 1.00 & & & & \\
\hline 16. D13 & 0.08 & 0.02 & 0.08 & -0.02 & 0.10 & -0.02 & -0.10 & 0.00 & -0.11 & 0.28 & 0.08 & 0.10 & -0.02 & 0.02 & 0.70 & 1.00 & & & \\
\hline 17. D14 & 0.07 & -0.03 & 0.17 & 0.15 & 0.07 & -0.01 & 0.05 & -0.01 & 0.17 & 0.08 & -0.06 & 0.14 & 0.21 & 0.36 & 0.32 & 0.22 & 1.00 & & \\
\hline 18. D15 & 0.13 & 0.23 & 0.14 & 0.14 & 0.26 & 0.02 & -0.06 & -0.08 & 0.04 & 0.08 & 0.22 & 0.13 & 0.19 & 0.04 & 0.13 & 0.25 & 0.07 & 1.00 & \\
\hline 19. D16 & 0.17 & 0.05 & 0.18 & 0.14 & 0.14 & 0.08 & 0.16 & 0.04 & 0.10 & 0.14 & 0.00 & 0.19 & 0.16 & 0.23 & 0.35 & 0.27 & 0.54 & 0.23 & 1.00 \\
\hline
\end{tabular}

${ }^{\mathrm{d}} 1=$ Search using dealer visits (DV); $2=$ Search on PRINT;3=Search on Dealer Websites (DW); 4=Search on Resale Websites (RW);5=Time spent talking to friends/ relatives (WOM);6=Experience of used cars(EUC); 7=log of wage rate (WAGE); $8=$ AGE ;9=number of models considered (MODELS); 10=helpfulness of DV; 11=helpfulness of PRINT; 12=helpfulness of DW;13=helpfulness of RW; 14= consumers' frequency of Internet use (D11); $15=$ consumers' enjoyment of store visit (D12);16= Consumers' enjoyment of talking to salespeople (D13); 17=Consumers' tendency to do price comparison (D14) 18=Consumers' interest in reading car enthusiast magazines (D15); 19=Consumers' enjoyment to gather information (D16) 
Table 5

Makes and models considered and seller type chosen by respondents

\begin{tabular}{ccc}
\hline $\begin{array}{c}\text { Number of makes } \\
\text { and models } \\
\text { considered }\end{array}$ & Number of respondents & \% of respondents \\
\hline 1 & 55 & 23.01 \\
2 & 79 & 33.05 \\
3 & 62 & 25.94 \\
4 & 43 & 17.99 \\
\hline
\end{tabular}

\begin{tabular}{ccc}
\hline Type of seller & $\begin{array}{c}\text { Number of respondents } \\
\text { who bought from this seller type }\end{array}$ & \% of respondents \\
\hline New car Dealer & 82 & 34.31 \\
Used car Dealer & 67 & 28.03 \\
Used car superstore & 18 & 7.53 \\
Individual seller & 72 & 30.13 \\
\hline
\end{tabular}

Table 6

Information sources used

\begin{tabular}{lc}
\hline $\begin{array}{c}\text { Information Source } \\
\text { for Car Search }\end{array}$ & $\begin{array}{c}\text { \% of Respondents } \\
\text { who used this Source }\end{array}$ \\
\hline Reading newspapers & $35 \%$ \\
Classified advertisements & $34 \%$ \\
Friends/relatives/individuals & $38 \%$ \\
Dealer visits & $70 \%$ \\
Newspaper websites & $31 \%$ \\
Manufacturer websites & $47 \%$ \\
Dealer websites & $62 \%$ \\
Used car superstore websites & $57 \%$ \\
Online referral websites & $30 \%$ \\
Third party websites & $46 \%$ \\
Auction websites & $29 \%$ \\
Local websites & $52 \%$ \\
\hline
\end{tabular}


Table 7

Exclusion Restriction Variables for different Information Sources

\begin{tabular}{lcccc}
\hline Exclusion Restriction Variable & $\begin{array}{c}\text { Dealer } \\
\text { visit } \\
(\mathbf{y} \mathbf{1})\end{array}$ & $\begin{array}{c}\text { Print } \\
(\mathbf{y} 2)\end{array}$ & $\begin{array}{c}\text { Dealer } \\
\text { website } \\
(\mathbf{y 3})\end{array}$ & $\begin{array}{c}\text { Resale } \\
\text { website } \\
(\mathbf{y} 4)\end{array}$ \\
\hline Frequency of Internet use & 0 & 0 & 1 & 1 \\
Enjoy store visit & 1 & 0 & 0 & 0 \\
Enjoy talking to sales people & 1 & 0 & 0 & 0 \\
Enjoy price comparison & 0 & 0 & 1 & 1 \\
Read car enthusiast magazines & 0 & 1 & 0 & 0 \\
Enjoy gathering information & 0 & 1 & 1 & 1 \\
Helpfulness of dealer visit & 1 & 0 & 0 & 0 \\
Helpfulness of print & 0 & 1 & 0 & 0 \\
Helpfulness of dealer websites & 0 & 0 & 1 & 0 \\
Helpfulness of resale websites & 0 & 0 & 0 & 1 \\
\hline
\end{tabular}

e " 1 " if variable is used as an exclusion restriction variable for the information source.

Table 8

Summary of hypotheses and their empirical support

\section{Hypothesis}

Support

H1.Offline search is positively associated with online search in the used car market, i.e., the more consumers do offline search, the more they will do online search.

$\mathrm{H} 2 \mathrm{a}$.Search on dealer website is positively associated with offline search in the used car market.

$\mathrm{H} 2 \mathrm{~b}$. Search on dealer website is negatively associated with offline search in the used car market.

$\mathrm{H} 3 \mathrm{a}$. Search on resale website is positively associated with offline search in $\quad \mathrm{X}$ the used car market.

$\mathrm{H} 3 \mathrm{~b}$. Search on resale website is negatively associated with offline search in $\quad \sqrt{ }$ the used car market.

H4a: Search on dealer website is positively associated with search on resale $\quad V$ website in the used car market.

H4b: Search on resale website is negatively associated with search on dealer website in the used car market.

${ }^{\mathrm{f}}$ X-represents hypothesis rejected; $\sqrt{ }$ represents hypothesis supported 
Table 9

Interrelationship of traditional and Internet information sources

\begin{tabular}{|c|c|c|c|c|c|c|c|c|c|c|c|c|}
\hline \multirow[b]{3}{*}{$\begin{array}{l}\text { RHS } \\
\text { ENDOGENOUS } \\
\text { VARIABLE } \\
\end{array}$} & \multicolumn{12}{|c|}{ DEPENDENT VARIABLE } \\
\hline & Deale & Visit & & Print & & & Dealer I & Vebsite & $\Delta$ & Resale & & \\
\hline & Est. ${ }^{\mathrm{g}}$ & Std. & $\begin{array}{c}\text { Mean } \\
\text { Value } \\
\text { Elasticity } \\
\end{array}$ & Est. & Std. & $\begin{array}{c}\text { Mean } \\
\text { Value } \\
\text { Elasticity } \\
\end{array}$ & Est. & Std. & $\begin{array}{c}\text { Mean } \\
\text { Value } \\
\text { Elasticity } \\
\end{array}$ & Est. & Std. & $\begin{array}{c}\text { Mean } \\
\text { Value } \\
\text { Elasticity }\end{array}$ \\
\hline Dealer Visit & & & & -0.43 & 0.02 & -2.49 & 0.59 & 0.05 & 0.37 & -1.65 & 0.15 & -0.91 \\
\hline Print & -1.15 & 0.05 & -0.20 & & & & 1.89 & 0.07 & 0.20 & 0.59 & 0.06 & 0.06 \\
\hline Dealer Website & 0.78 & 0.02 & 1.27 & 0.53 & 0.01 & 4.99 & & & & 0.24 & 0.05 & 0.21 \\
\hline Resale Website & -0.28 & 0.03 & -0.51 & -0.05 & 0.01 & -0.52 & -0.02 & 0.01 & -0.02 & & & \\
\hline
\end{tabular}

g Bold are significant at $95 \%$ level, *significant at $90 \%$ level. We followed the Bayesian approach of considering coefficients in which the 95\% HDPI does not include zero to be significant. Refer to Koop (2003), page 52.

${ }^{\mathrm{h}}$ Calculated as: coefficient* ${ }^{*}$ mean of $\mathrm{x} /$ mean of $\left.\mathrm{y}\right)$. Means are: Dealer Visit $=3.24$; Print $=.56$; Dealer Website $=5.27$; Resale

Website $=5.86($ see Table 3$)$. 
Table 10

Factors influencing information source use

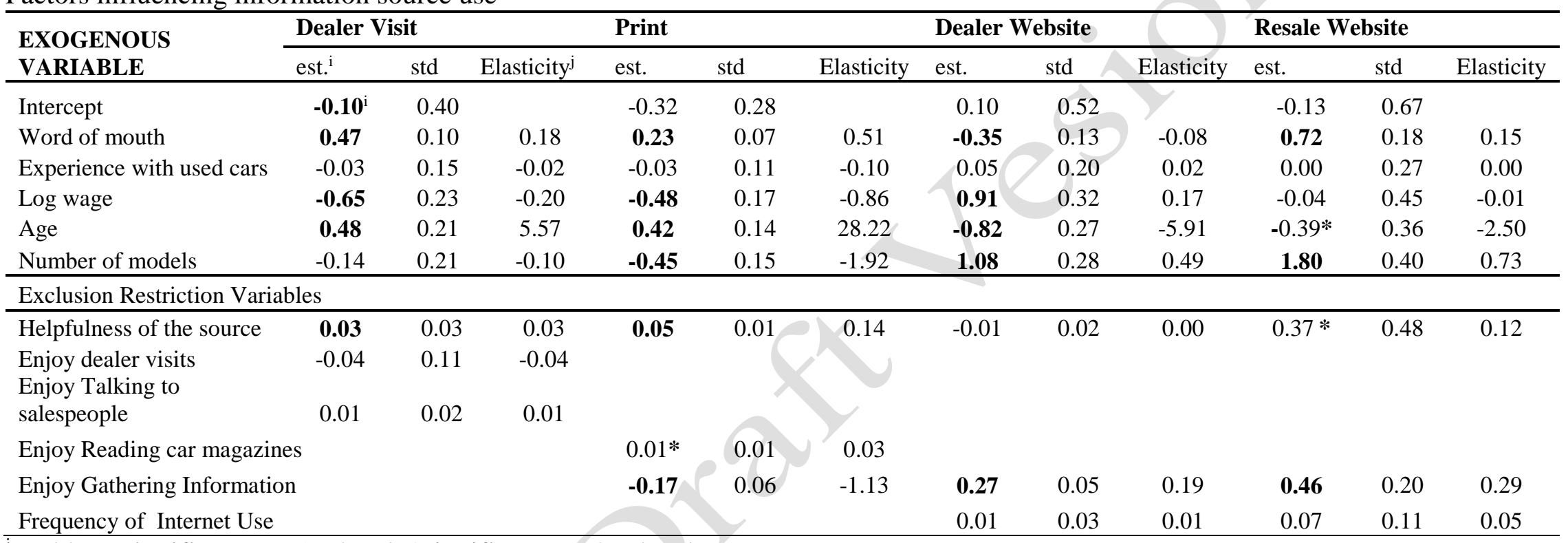

${ }^{\mathrm{i}}$ Bold are significant at $95 \%$ level, *significant at $90 \%$ level

${ }^{\mathrm{j}}$ Calculated as: coefficient*(mean of $\mathrm{x} /$ mean of $\left.\mathrm{y}\right)$, except for log wage. The latter is coefficient*(1/mean of $\left.y\right)$. 
Table 11

Seller choice model- conditional logit analysis

\begin{tabular}{lc}
\hline Dependent Variable- Seller choice & Model Fit Summary \\
\hline Number of Observations & 239 \\
Log Likelihood & -199.02475 \\
Log Likelihood Null & -331.32435 \\
AIC & 472.04949 \\
Schwarz Criterion & 600.67865 \\
\hline
\end{tabular}

Discrete Response Profile

\begin{tabular}{llcc} 
Alternative & Seller type & Frequency & Percent \\
\hline 1 & New Car Dealer (NCD) & 82 & 34.31 \\
2 & Used Car Dealer (UCD) & 67 & 28.03 \\
3 & Used Car Superstore (UCS) & 18 & 7.53 \\
4 & ${\text { Individual Seller (IS) }{ }^{\mathrm{k}}}$ & 72 & 30.13 \\
\hline
\end{tabular}

${ }^{\mathrm{k}}$ Individual seller is the base category for comparison.

Conditional Logit Estimates

\begin{tabular}{lcccc}
\hline Variable & est. & std & t value & Pr >|t $\mid$ \\
\hline Intercept -NCD & 1.16 & 1.87 & 0.62 & 0.54 \\
Intercept -UCD & -0.20 & 1.83 & -0.11 & 0.91 \\
Intercept -UCS & 0.93 & 2.68 & 0.35 & 0.73 \\
Trust & $\mathbf{1 . 3 1}$ & 0.18 & 7.14 & $<.0001$ \\
\hline USE OF INFORMATION SOURCES-DEPTH & OF SEARCH & & \\
\hline Dealer visit-NCD & $\mathbf{0 . 2 5}$ & 0.09 & 2.66 & 0.01 \\
Dealer visit-UCD & $\mathbf{0 . 3 0}$ & 0.09 & 3.27 & 0.00 \\
Dealer visit-UCS & $0.23^{*}$ & 0.15 & 1.59 & 0.11 \\
Print -NCD & 0.05 & 0.23 & 0.22 & 0.83 \\
Print -UCD & 0.07 & 0.16 & 0.44 & 0.66 \\
Print -UCS & 0.01 & 0.40 & 0.03 & 0.98 \\
Retail websites-NCD & 0.04 & 0.06 & 0.66 & 0.51 \\
Retail websites-UCD & $0.08^{*}$ & 0.05 & 1.62 & 0.10 \\
Retail websites-UCS & 0.11 & 0.08 & 1.36 & 0.17 \\
Resale websites -NCD & $\mathbf{- 0 . 1 6}$ & 0.05 & -3.15 & 0.00 \\
Resale websites -UCD & $\mathbf{- 0 . 0 6}$ & 0.03 & -1.83 & 0.07 \\
Resale websites -UCS & $\mathbf{- 0 . 3 9}$ & 0.15 & -2.55 & 0.01 \\
\hline
\end{tabular}


Table 11 (continued)

\begin{tabular}{lcccc}
\hline Variable & est. & std & t value & $\mathrm{Pr}>|\mathrm{t}|$ \\
\hline \multicolumn{1}{l}{ DEMOGRAPHIC CHARACTERISTICS } & & & \\
\hline No of models considered-NCD & $\mathbf{- 0 . 4 6}$ & 0.23 & -2.04 & 0.04 \\
No of models considered-UCD & $\mathbf{- 0 . 5 4}$ & 0.22 & -2.44 & 0.01 \\
No of models considered-UCS & -0.09 & 0.38 & -0.25 & 0.80 \\
Price range-NCD & $\mathbf{0 . 7 0}$ & 0.30 & 2.33 & 0.02 \\
Price range-UCD & $\mathbf{0 . 7 7}$ & 0.30 & 2.53 & 0.01 \\
Price range-UCS & $\mathbf{1 . 1 8}$ & 0.40 & 2.93 & 0.00 \\
Age-NCD & $\mathbf{0 . 5 9}$ & 0.22 & 2.69 & 0.01 \\
Age-UCD & $\mathbf{0 . 3 9}$ & 0.23 & 1.71 & 0.09 \\
Age-UCS & 0.50 & 0.32 & 1.56 & 0.12 \\
Years of schooling-NCD & -0.14 & 0.09 & -1.52 & 0.13 \\
Years of schooling -UCD & 0.04 & 0.09 & 0.45 & 0.65 \\
Years of schooling -UCS & 0.06 & 0.17 & 0.38 & 0.70 \\
No of children-NCD & 0.20 & 0.21 & 0.98 & 0.33 \\
No of children-UCD & 0.26 & 0.20 & 1.32 & 0.19 \\
No of children-UCS & 0.17 & 0.31 & 0.55 & 0.59 \\
Logwage-NCD & -0.28 & 0.45 & -0.61 & 0.54 \\
Logwage-UCD & $\mathbf{- 0 . 9 4}$ & 0.48 & -1.97 & 0.05 \\
Logwage-UCS & $\mathbf{- 2 . 2 7}$ & 0.84 & -2.71 & 0.01 \\
Experience of used cars-NCD & $-0.23 *$ & 0.14 & -1.67 & 0.10 \\
Experience of used cars-UCD & 0.05 & 0.13 & 0.38 & 0.70 \\
Experience of used cars-UCS & 0.06 & 0.20 & 0.28 & 0.78 \\
\hline Bold are & & & &
\end{tabular}

1 Bold are significant at 95\% level. * significant at 90\% level 